\title{
Mariusz Krajcarz
}

Uniwersytet im. Adama Mickiewicza w Poznaniu

\section{Ältere niederländische und polnische Bibelübersetzungen}

Es ist allgemein bekannt, dass die Bibel der Entwicklung der europäischen Sprachen und Literaturen zugrunde liegt. Die Bibelübersetzungen haben zur Herausbildung der Schriftsprachen des europäischen Kulturkreises, zu dem das Niederländische (im Folgenden: N1.) und das Polnische (im Folgenden: Pl.) gehören, wesentlich beigetragen ${ }^{1}$. Im Prozess der Übertragung der Heiligen Schrift wurde die Schriftsprache geboren, die sich durch ihren Wortschatz und Stil von der Umgangssprache immer mehr unterschied.

Es besteht kein Zweifel darüber, dass die Bibelübersetzungen auch in großem Maße die lexikalischen und phraseologischen Wortschätze des N1. und des Pl. bereichert haben ${ }^{2}$. Die auf Grund von Bibelübersetzungen entstandenen Bibelphraseme, d. h. feste Wortgruppen biblischen Ursprungs, beeinflussten die allgemeine Sprache. Als besondere Bestandteile der nl. (im Folgenden nl.) und pl. (im Folgenden pl.) Sprache sind sie sprachliche Zeugnisse der gesamten christlichen Tradition und Kultur beider Nationen. Die Zahl der Bibelphraseme ist in jeder der untersuchten Sprache offen und hängt vom Tempo der Sprachentwicklung ab: die einen veralten und werden allmählich ungebräuchlich, die anderen gehen mit der Zeit ins allgemeine Sprachregister ein.

Das Ziel der vorliegenden Darstellung ist es, einen historischen Überblick über die älteren nl. und pl. Bibelübersetzungen bis einschließlich die in der Re-

${ }^{1}$ Zur kulturbildenden Rolle der Bibelübersetzungen Vgl. T. Lewaszkiewicz, Rola przekładów Biblii w formowaniu się języków literackich europejskiego kręgu kulturowego, [in:] Biblia a kultura Europy, hrsg. von M. Kamińska, E. Małek, Bd. I, Łódź 1992, S. 232-248. Auch R. Rubinkiewicz, Kulturotwórcza rola Biblii w historii Europy, [in:] Idee chrześcijańskie w życiu Europejczyka, hrsg. von A. Ceglińska, Z. Staszewska, Bd. I, Łódź 2001, S. 17-28.

${ }^{2}$ B. Walczak, Rola Biblii w rozwoju języków i językoznawstwa. Zarys problematyki, [in:] Inspiracje chrześcijańskie w kulturze Europy, Łódź 2000, S. 155-167. 
formationszeit erschienenen „Staatenbibel” vs „Wujek-Bibel” zu geben. Zuerst werden die nl., dann die pl. Bibelübersetzungen der Reihe nach besprochen, wobei kein Anspruch auf Vollständigkeit der Darstellung erhoben wird. Ältere Bibelübersetzungen (1.1. und 1.2.) werden nur allgemein dargestellt. Mehr Aufmerksamkeit wird der „Staatenbibel” (2.1.) und der „Wujek-Bibel” (3.) (Entstehung, Charakteristik der Übertragung, Rolle in der Sprachentwicklung) gewidmet, da beide Übersetzungen einen besonderen Platz in der Sprachgeschichte einnehmen.

\section{1. Ältere nl. und pl. Bibelübersetzungen}

\section{1. Ältere nl. Bibelübersetzungen}

Das Christentum kam nach Flandern und in die Niederlande mit der lateinischen Bibelübersetzung Vulgata, die wiederum auf dem hebräischen, aramäischen (das Alte Testament) und griechischen (das Neue Testament) Urtext basierte. Nach einiger Zeit entstanden daneben Übersetzungen und Bearbeitungen von Bibelfragmenten aus dem Lateinischen in die Volkssprache ${ }^{3}$.

Die ältesten Texte, die im Nl. überliefert wurden, sind Bearbeitungen von Bibelbüchern. Zu ihnen gehören unter anderem die „Wachtendoncker Psalmen” aus dem 11. Jh. und der „Leidener Willeram”, eine Paraphrase des Hohen Liedes vermutlich aus dem 11. Jh. Diese altniederländischen Texte sind noch stark vom deutschen Urtext beeinflusst und lediglich fragmentarisch überliefert worden.

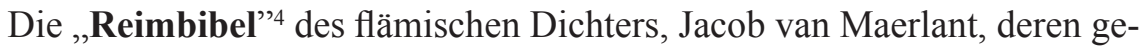
naues Entstehungsdatum auf 1271 fällt, ist auch eine Bearbeitung, und zwar der lateinischen Historia Scholastica von Petrus Comestor. In diesem gereimten Text wurden die Bibelerzählung und andere Informationen (historische

${ }^{3}$ In eine Chronik aus dem 11. Jh., die im Kloster St.-Riquier zu Ponthieu aufbewahrt wird, wurde ein Katalog der dortigen Bibliothek aufgenommen. Er erwähnt unter anderem ein in der Volkssprache verfasstes Schriftstück über das Leiden von Christus mit dem lateinischen Titel: Passio Domini in theodisco et in Latino 'Das Leiden unseres Herrn, in Diets und in Lateinisch'. Diets, abgeleitet vom 'diet' = 'Volk', bedeutet Volkssprache, Sprache des Volkes. Es wurde später zur allgemeinen Bezeichnung für das Mittelniederländische, d. h. das Nl., wie es mit vielen mundartlichen Unterschieden, vom ca. 1200 bis ca. 1550 gesprochen wurde. Vgl. J. van Delden, Spreekwoorden en zegswijzen uit de bijbel, Utrecht 1990, S. 30-31.

${ }^{4}$ J. van Maerlant, Rijmbijbel, [in:] Corpus van Middelnederlandse teksten (tot en met het jaar 1300) [...], Reihe II, Bd. 1, 's-Gravenhage 1983. Eine ausführliche Bibliographie über alle angeführten nl. Bibelübersetzungen befindet sich in der Monograhie von K. van Dalen-Oskam, M. Mooijaart, Bijbels lexicon. Woorden en uitdrukkingen uit de Bijbel in het Nederlands van nu, Amsterdam 2000, Literatuur: Bijbelvertalingen, S. 433-434. 
Erklärungen, Vermerke und Kommentare) miteinander verflochten. Die Bearbeitung machte Jahrhunderte lang ihren Einfluss geltend ${ }^{5}$.

Auf die Reimbibel (1271) lassen sich gegenwärtig geläufige Bibelphraseme zurückführen wie: het dagelijks brood, niet bij brood alleen, hosanna roepen (zingen), judaspenning, door het oog van de naald kruipen ect. ${ }^{6}$ In dieser Periode wurden auch Evangelienkonkordanzen (nl. „evangelieënharmoniën”) auf Grund der vier Evangelien: Matthäus, Markus, Lukas und Johannes zu einer ganzheitlich bearbeiteten Erzählung über das Leben von Jesus schriftlich verfasst. Das „Lütticher Diatessaron” (circa 1291-1300) ist eines von ihnen?.

Aus dem Ende des 13. Jh.'s, Anfang des 14. Jh.'s datieren noch verschiedene Bearbeitungen von Bibelbüchern, unter anderem von Psalmen, Evangelien und Apostelbriefen. Sie stammen vorwiegend aus den südlichen Provinzen: Flandern und Brabant, die auf kulturellem und wirtschaftlichem Gebiet eine geraume Zeit den Ton angaben. Alle diese Texte waren in ziemlich großem Umfang verbreitet, sowohl in den Niederlanden als auch im deutschen Rheingebiet. Ihre Leser waren Mönche und wohlhabende Bürger.

In den nächsten Jahrhunderten wurden allmählich immer mehr Übersetzungen veröffentlicht, mal von einem oder einigen Bibelbüchern, mal vom Alten oder Neuen Testament als Ganzes. Es wurden einige historische Bibeln ${ }^{8}$

${ }^{5}$ Maerlants Werk wird jedoch nicht zu den Bibelübersetzungen im eigentlichen Sinne zugerechnet. Vgl. ebd., S. 31.

${ }^{6}$ Die prototypischen Beispiele werden dem schon erwähnten Bibel-Lexikon von K. van Dalen-Oskam, M. Mooijaart entnommen: Het dagelijks brood (v.22724): Ghef ons dat daghelixe brod (Geef ons het dagelijks brood.); Niet bij brood alleen (v.22230-31) Jhesus sprac niet ne leuet die man. / Allene bi den broede dan. (Jesus sprak: De mens leeft niet alleen van het broood.) usw. Weitere Beispiele siehe, ebd.

${ }^{7}$ Die älteste mittelniederländische Übersetzung ist das „Leven van Jesus”, eine Bearbeitung der lateinischen Evangelienharmonie, die auf das Diatessaron von Tatianus zurückgeht (gr. 'durch vier hin'). Diese 'Verdietsung', gemacht um 1280, die wahrscheinlich aus dem Kreis von Willem van Afflingem, Abt im Kloster St. Truiden in Limburg, stammt, ist ein unübertroffenes Kunstwerk inmitten von zahlreichen mittelmäßigen Übersetzungen. In De ontwikkelingsgang der Nederlandsche letterkunde stellt J. te Winkel fest, dass das Leven van Jesus, kurz nach seiner Entstehung, relativ weit verbreitet war und als „een voorbeeld van helder en ongekunsteld Dietsch proza, boeiend door frisheid en natuurlijkheid, zonder ooit tot platheid te vervallen, zoodat de verheven eenvoud der evangeliën misschien in geen enkele andere Nederlandsche vertaling, van welken tijd ook, zoo duidelijk uitkomt als in dit geschrift" galt. Zitiert nach J. van Delden, ebd., S. 32.

8 „Historiebibel” ist die Bezeichnung für die freie Prosaparaphrase der erzählenden Teile der Bibel. Fast alle Historiebibeln basieren auf der Historia scholastica von Petrus Comestor (ca. 1175), und dienten didaktischen Zwecken. Von der sog. Ersten Historiebibel im Mittelniederländischen (vermutlich aus 1358) sind lediglich einige wenige Exemplare erhalten geblieben. Bekannter ist die sog. Zweite Historiebibel, die 1360-1361) entstand und mehr Bibeltext beinhaltete. Mit dem Aufbruch des Humanismus und der Erscheinung von Bibelübersetzungen von Martin 
überliefert, ferner Übersetzungen von Psalmen, Evangelien und Apostelbriefen. Ein Impuls ging unter anderem von der „Modernen Devotie” aus9. Diese Texte wurden in zahlreichen Exemplaren in den Niederlanden und in Niederdeutschland verbreitet.

Die erste 1477 im Druck erschienene Bibel war die sog. „Delfter Bibel”10, in der Übersetzung aus dem Jahr 1360. Sie bestand aus zwei Teilen, enthielt aber nur das Alte Testament, wobei auch die Psalmen weggelassen wurden ${ }^{11}$.

Im 16. Jh. wurde die Bibel Allgemeingut dank der Buchdruckkunst und der geänderten religiösen Anschauungen. Auf Grund von Martin Luthers Bibelübersetzung ins Deutsche von 1522 (das Neue Testament) wurden auch neue nl. Übersetzungen angefertigt. Schon ein Jahr später erschien in Amsterdam und in Antwerpen die Übersetzung des Lutherschen Neuen Testaments, die für die erste reformatorische nl. Bibelübersetzung gehalten wird. Vielfach wurde dieses Neue Testament, trotz der kaiserlichen Verfolgung gegen die Ketzerbücher, neu gedruckt. Zwei Jahre später erblickte Luthers Alte Testament das Tageslicht, so dass 1525 die ganze Bibel in der niederländischsprachigen Ausgabe im Handel erhältlich war.

Verschiedene, miteinander konkurrierende Verlage brachten in jenen Jahren zahlreiche Bibelausgaben auf den Büchermarkt. Großer Popularität erfreuten sich zahlreiche Mischausgaben, worin sich der Luthertext mit kürzeren oder längeren Fragmenten aus dem „Delfter Neuen Testament” nach Erasmus (1524) abwechselte.

Solch eine erwähnenswerte Ausgabe, die jedoch noch bunter zusammengestellt war, war die „Vorsterman-Bibel”. Diese durch den flämischen Buchdrucker, -binder und -verkäufer Willem Vorsterman im Jahre 1528 in Antwer-

Luther hatte die Autorität der Historiebibel ein Ende. Vgl. Encarta ${ }^{\circledR}$ Naslagbibliotheek - Winkler Prins. (C) 2007, Microsoft Corporation/Het Spectrum, Stichwort: 'Historiebijbel'.

${ }^{9}$ Im Stundenbuch von Geert Groote (1340-1384), dem geistlichen Vater der Moderne Devotie, trifft man die ins Mittelniederländische übersetzten Psalmen an, so dass in jedem Fall in der zweiten Hälfte des 14. Jh.'s auch in den Nordniederlanden mit der Bibelübersetzung ein Anfang gemacht worden war. Groote's Werk wurde unter anderem von seinem eifrigen Lehrling, Johan Schutken, fortgesetzt. Zu den Verdiensten dieses 'pater devotus' aus dem Kloster Windesheim in Overijssel gehört die Übersetzung des ganzen Neuen Testaments (1477) und der Psalmen (1480) 'ex latino in teutonicum', aus dem Lateinischen ins Dietse. J. van Delden, ebd., S. 33.

${ }^{10}$ De Delftse bijbel van 1477. Fascimile van de oorspronkelijke druk met de inleiding van C.C. de Bruin, 1977.

${ }^{11}$ Ungefähr in derselben Zeit (1478) erschien in Köln eine vollständige Bibelübersetzung in der westniederdeutschen und niederrheinischen Mundart im Druck. Diese „Kölnische Bibel”, herausgegeben in zwei stattlichen, reich illustrierten Bänden, konnte auch in den Niederlanden viel gelesen werden, - vorläufig - aus Mangel an einer vollständigen Ausgabe in der eigenen Sprache. Ebd., S. 34. 
pen herausgegebene Bibel ist ein Mosaik von katholischen, Erasmusschen und Lutherschen Texten ${ }^{12}$.

Die erste vollständige Bibel in der nl. Sprache wurde 1526 von Jacob van Liesveldt in Antwerpen gedruckt. Schon in der Erstausgabe der „LiesveldtBibel"13, vor allem aber in späteren Ausgaben erschienen immer mehr reformatorische Randbemerkungen und Kommentare, mit antikatholischen Illustrationen ausgestattet, wofür der Verleger letztendlich mit seinem Leben bezahlen musste ${ }^{14}$.

Unter der zunehmenden Ketzerverfolgung unter Karl dem V und der sich immer mehr ausbreitenden spanisch-habsburgischen Inquisition verließen mehr Reformierte das Land. Sie wichen unter anderem ins deutsche Ostfriesland aus, wo die Stadt Emden zum Bollwerk des Protestantismus wurde und zum Zentrum, von dem aus die Bibel in verschiedenen Auflagen verbreitet wurde.

Der Text jener „Liesveldt-Bibel”, die 1545 in Antwerpen zu so grausamen Konsequenzen geführt hatte, wurde in Emden mehrfach nachgedruckt. Dieser Text, der auf der Luther-Übersetzung fußte, war allen reformierten Gruppen der Niederlande bis zur Jahrhundertmitte gemeinsam ${ }^{15}$.

Der Liesveldt-Bibel (1526) haben wir u. a. die heute im Sprachgebrauch geläufigen Phraseme ${ }^{16}$ zu verdanken, wie

(1) Zich niet onbetuigd laten (Apg 14,17): Tis waer hi en heeft hem seluen niet ombetuycht ghelaten;

(2) Het ene doen en het andere niet laten (Luk 11,42): Dit soude men doen, ende tgene niet laten;

(3) De dood in de pot (2. Kön 4,40): Ende doen [...] si vanden moes aten, riepen si en seiden: O Man Gods, den doot inden pot, want si en constens niet geten;

(4) In den beginne (1. Mose 1,1): In den beginne sciep God hemel ende aerde;

(5) Velen zijn geroepen, maar weinigen uitverkoren (Matth 20,16): Want vele zijn geroepen, maer weinich wt uercoren.

${ }^{12}$ Diese Bibel basiert, wenn es um die Texte geht, auf der Vulgata und auf der Übersetzung von Erasmus, aber in den Randbemerkungen folgt sie der Lehre Luthers. Die im katholischen Geist geschriebene Einleitung kann als ein die Behörde irreführender Versuch angesehen werden, was auch einen zeitlich begrenzten Erfolg mit sich brachte. 1546 wurde das Werk auf den Index (librorum prohibitorum) gesetzt. Ebd., S. 35.

${ }_{13}$ Dat oude ende dat nieuve testament. Gheprint... by my Jacob van Liesueldt..., Antwerpen 1526.

${ }^{14}$ Vor allem die Randbemerkung im Druck aus dem Jahre 1542 'dat de salicheyt der menschen alleen compt door Jesum Christum' erweckte die Wut der katholischen Kirchenbehörde, und da Liesveldt nicht nachgeben wollte, wurde er am 28. November 1545 enthauptet. Ebd., S. 36.

${ }_{15}$ Vgl. P.H. Vogel, Der niederländische Bibeldruck in Emden 1556-1568, „GutenbergJahrbuch" 1961, S. 162-171.

${ }^{16}$ Die Beispiele nach Bibel-Lexikon 2000 von K. van Dalen-Oskam, M. Mooijaart, ebd. 
Neben den Reformierten gab es die große Gruppe der Taufgesinnten, die ihre Bibel ebenfalls vor allem aus Emden bezogen. Es handelt sich dabei um die „Biestkens-Bibel”, so genannt nach dem Buchdrucker Nicolaes Biestkens, der erstmals 1560 eine Bibel mit seinem Druckvermerk veröffentlichte. Dieser Bibel liegt die Luther-Übersetzung in die niederdeutsche Mundart zugrunde. Sie wurde lange Zeit in anabaptistischen Kreisen gelesen ${ }^{17}$.

Inzwischen verlangten die Kalvinisten eine getreue Übersetzung direkt aus den Originalsprachen. Deshalb übersetzte der Flame Jan Utenhove aus Gent, direkt aus dem Griechischen, das Neue Testament (Emden 1556), das sich aber wegen der eigenartigen Sprachformen nicht durchsetzen konnte ${ }^{18}$.

Mehr Erfolg hatte dagegen die von Johannes Dyrkinus (Emden 1559) angefertigte Übersetzung des Neuen Testaments aus der Originalsprache, dem Griechischen, wobei sich der Autor unter anderem auf die oben genannte Übersetzung von Utenhove stützte. Dieses Werk wurde samt der Lutherschen Übersetzung des Alten Testaments durch Gottfried van Winghen zu einer vollständigen Emder Bibel vereinigt, 1561-1562 erschienen und meistens die „Deux-aes-Bibel” ${ }^{19}$ oder die „Bibel von deux-aes” genannt ${ }^{20}$, die bis zum Erscheinen der „Staatenbibel” im Jahre 1637 die maßgeblichste und einflussreichste Bibel der nl. Reformierten sein sollte.

Die verbesserte Vulgata diente als Grundlage für die von der katholischen Kirche autorisierten Bibelübersetzung von Nicolaas van Winghe, einem re-

${ }^{17}$ Diese „Biestkens-Bibel” bringt den nl. Text erstmals in Verseinteilung „tot voorderinge van den Leezer, om terstond te vinden 't geene dat hy soekt", was zu jener Zeit ein Novum war. Ebd., S. 37. P.H. Vogel fügt hinzu, dass sie sich auch durch ein kleines, handliches Format auszeichnete, das einen niedrigen Preis bedeutete. Außerdem bot sie auch eine gute Möglichkeit, das Buch versteckt zu halten. Der anabaptistische Bezug wird vor allem in den Registern fassbar, wo Begriffe wie 'Bann', 'Eid' oder 'Taufe' eine zentrale Rolle spielen. Mehr dazu bei P.H. Vogel, ebd.

${ }^{18}$ Utenhove verwendete dazu eine 'künstliche Mischsprache', zusammengesetzt aus verschiedenen, vor allem östlichen Dialekten, weil die Bibel für die aus den Niederlanden emigrierten reformatorischen Gläubigen im norddeutschen Emden bestimmt war. Aber diese Sprache war zu weit entfernt von der gebräuchlichen Schriftsprache, und die östlichen Dialekte wurden außerdem in dieser Zeit als eine minderwertige Mischung aus Niederländisch und Deutsch betrachtet und vom Westen abgelehnt. Diese Übersetzung konnte sich folglich nicht durchsetzen. Mehr dazu im Kapitel 8.2. bei M. Van der Waal, Geschiedenis van het Nederlands, Utrecht 1994.

19 Biblia: Dat is, de gantsche Heylighe Schrift... verduydtschet, Embden 1562.

${ }^{20}$ Dieser charakteristische Name erklärt sich aus einer Marginalie zu Nehemia 3.5, die von einem Würfelspiel herrührt: „De armen moeten het cruyce dragen, de rijcke en geven niets, deux aes en heeft niet, six cincque en gheeft niet, quater dry die helpen vrij", was sinngemäß heißen soll: Die Armen (deux, aes = zwei, eins) haben nichts, die Reichen (six, cinque = sechs, fünf) geben nichts, aber der Mittelstand (quater, dry $=$ vier, drei) hilft bereitwillig. Vgl. P.H. Vogel, ebd., S. $162-171$. 
gulären Kanoniker aus Löwen. Die „Löwener Bibel”21 aus 1548, vielmals in Antwerpen neu gedruckt, und ihre Nachfolgerin, die von 1599 stammende „Moerentof-Bibel”22, wurde jahrhundertlang (bis zum 19. Jh.) zur Bibel der katholischen Gläubigen.

\section{2. Ältere pl. Bibelübersetzungen}

Als Anfang des Christentums in Polen gilt - wie allgemein bekannt - das historische Datum der Taufe Polens im Jahre 966. Damals entstanden die ersten biblischen Texte, die als Übersetzungen in die verwandten Sprachen, ins Tschechische und Altslawische bekannt waren ${ }^{23}$. Vor allem während der Predigten wurden diese Bibelzitate mündlich ins Polnische übertragen.

Aus den drei ersten Jahrhunderten des Christentums in Polen (10.-12. Jh.) hat sich jedoch keine schriftliche Übersetzung mehr erhalten. Die ältesten Versuche, die Bibel ins Pl. zu übersetzen, stammen aus den mittelalterlichen Sammlungen pl. Predigten. Zu den bekanntesten gehören: die „Heilig-KreuzPredigten” (Hälfte des 14. Jh.'s) ${ }^{24}$ und die „Gnesener Predigten” (Anfang des 15. Jh.'s), überliefert in der Form der sog. homiletischen Texten, also handgeschriebenen Absätzen aus den Evangelien oder anderen Bibelbüchern, die zu Beginn der Predigt vorgelesen und während der Predigt erklärt wurden.

Die älteste Handschrift mit pl. Übersetzung eines biblischen Textes, der sog. „Florianer Psalter”, entstand um die Jahrhundertwende vom 14. auf $15 \mathrm{Jh}$. Er wurde in der Abtei des hl. Florian zu Linz 1825 entdeckt und zum ersten Mal 1834 veröffentlicht. Es ist eine reich illuminierte Psalmensammlung in den lateinischer, deutscher und pl. Sprache.

Es erhielt sich auch ein reich geschmücktes Buch der Psalmen, der sog. „Puławer Psalter” vom Ende des 15. Jh.'s.

Die erste vollständige pl. Übersetzung des Alten Testaments, die in höfischen Büchersammlungen in der ersten Hälfte des 15. Jh.’s erschien, war die sog. „Königin-Sophie-Bibel”25. Diesen Namen hat sie der letzten Ehegattin

${ }^{21}$ Den gheheelen Bybel / Inhoudende het oude ende nieuwe Testament..., Leuven 1548.

22 Biblia Sacra. Dat is De geheele Heylighe Schrifture..., Antwerpen 1599.

23 Die allgemeinen Informationen werden dem Beitrag von M. Wojciechowski über die polnischen Übersetzungen entnommen [in:] Słownik wiedzy biblijnej, 3. Auflage, Warszawa 1999, S. 648-654 (im Folgenden SWB genannt). Das Lexikon wurde aus dem Englischen: The Oxfort Companion to the Bible (1993) übersetzt.

${ }^{24}$ Die Kopie des Manuskripts Kazania Świętokrzyskie stammt wahrscheinlich schon aus dem Ende des 13. Jh.'s oder Anfang des 14. Jhr.'s. Vgl. W. Wydra und W.R. Rzepka, Chrestomatia staropolska. Teksty do roku 1543, Wrocław 1984, S. 89.

${ }^{25}$ Biblia Królowej Zofii (Szaroszpatacka) wraz ze staroczeskim przekładem Biblii, hrsg. von S. Urbańczyk, V. Kyas, Wrocław-Warszawa-Kraków 1961. 
des pl. Königs Władysław Jagiełło, der Königin Sophie, zu verdanken, die die Schirmherrschaft über diese Übersetzung ausübte. Die Übersetzung aus der lateinischen Vulgata wurde von einer Übersetzergruppe unter Leitung von Andrzej aus Jaszowice angefertigt, die sich der vorhandenen tschechischen Übersetzungen bediente. Bis zum Zweiten Weltkrieg wurde lediglich ein Band dieser Handschrift erhalten. Es wurde in einem kalvinistischen Gymnasium in der ungarischen Stadt Sarospatak aufbewahrt. Daher trug die Bibel auch einen anderen Namen: die „Sarospataker Bibel”"26. Schon in dieser Übersetzung findet man zum Beispiel den Prototyp des gegenwärtig geläufigen Bibelphrasems oko za oko, zab za ząb $b^{27}$.

Nach der Erfindung des Buchdrucks waren einige der ersten Ausgaben mit biblischen Texten auch sehr oft die Psalter. Dies bestätigen die damals bekannten Bücher von Psalmen, die zu jener Zeit die Rolle der in der pl. Sprache fehlenden Gebetbücher ausübten. Sehr populär sind unter ihnen geworden: „Żołtarz Dawidów...” [„David-Psalter”] von 1539, die Psalmübersetzung in Prosa vom Priester Walenty Wróbel, Professor der Krakauer Akademie, sowie „Psałterz Dawidów” [,Psalter von David”] aus dem Jahre 1541 vom Dichter Mikołaj Reje.

In der Reformationszeit folgt eine richtige Flut von pl. Bibelübersetzungen.

Im Vorwort zu seiner Sammlung von Bibelphrasemen in der pl. Sprache „Mały słownik biblizmów języka polskiego" nennt Jan Godyń ${ }^{29}$ zwei Ursachen dieses Phänomens. Er schreibt:

${ }^{26}$ Während des Zweiten Weltkrieges ist der Band verloren gegangen, so dass nur einige, aus einem anderen Band übrig gebliebene Blätter vorliegen. Man weiß nicht, ob die „KöniginSophie-Bibel" auch das Neue Testament beinhaltete. Es steht jedoch fest, dass die Übersetzungen aus dem 15. Jh. die frühere polnische handschriftliche Übersetzung des Neuen Testaments berücksichtigten, die später leider verloren ging. SWB, S. 648.

${ }^{27}$ Siehe, Stownik staropolski, hrsg. von S. Urbańczyk, Bd. V, Wrocław 1965-1969, S. 553, Bd. XI, Kraków 1995-2002, S. 254. Über die altpolnischen Bibelphraseme, die als Prototyp der zeitgenössischen Formen fungieren, schreibt u. a. L. Moszyński in seinem Beitrag Kształt językowy potocznych frazeologizmów ewangelicznych w przekładach polskich. Od Murzynowskiego do Biblii Tysiaclecia, [in:] Idee chrześcijańskie w życiu Europejczyka, hrsg. von A. Ceglińska, Z. Staszewska, Bd. I, Łódź 2001, S. 301-328.

${ }^{28}$ Auch in der späteren Periode, als es schon Übersetzungen der ganzen Bibel gab, wurden die Psalmensammlungen getrennt herausgegeben, und zwar in der Form einer poetischen Paraphrase. Die größte Anerkennung erlang dann der Psalter von Jan Kochanowski aus 1579, unter dem Titel „Psałterz Dawidów...”, mit Musik von Mikołaj Gomółka aus 1580. Dieses Werk gilt in der Geschichte der polnischen Literatur als Höhepunkt der Poesie der polnischen Renaissance. Vgl. J. Godyń, Od Adama i Ewy zaczynać. Mały stownik biblizmów języka polskiego, Kraków-Warszawa 1995, S. 15.

${ }^{29}$ Ebd., S. 13. 
Pisarze i thumacze ze środowisk reformacyjnych stawiali sobie za cel nie tylko umożliwianie wiernym poznanie objawionego Słowa Bożego w języku rodzimym, ale za pomocą przekładów Biblii dążyli - nie bez znacznych sukcesów do pozyskania zwolenników dla swoich idei. W tej sytuacji Kościół katolicki też musiał przełamać swoją rezerwę, a nawet niechęć do upowszechniania Pisma św. w języku polskim i dać swoje imprimatur na tłumaczenia i druk Biblii, powstające w środowiskach katolickich. Biblia stała się wówczas narzędziem walki z przeciwnikami ideowymi i wyznaniowymi - rozpoczęła się swoista rywalizacja na kolejne przekłady między obozami reformacyjnym i katolickim ${ }^{30}$.

Als Beispiel dieses Wetteiferns können die ersten gedruckten pl. Übersetzungen des Neuen Testaments gelten. So erschien in den Jahren 1551-1553 in Königsberg in der Druckerei von Jan Suklecjan die erste evangelische Übersetzung des Neuen Testaments, deren Autor der Lutheraner Stanisław Murzynowski war (die sog. „Lutherische Königsberger Bibel”). Als eine Reaktion darauf kam die katholische Übersetzung des Neuen Testaments, die von Marcin Bielski angefertigt und 1556 in der Druckerei von Scharffenberg zu Krakau herausgegeben wurde.

Fünf Jahre später erschien in derselben Druckerei die erste pl. Übersetzung der ganzen Heiligen Schrift, die unter dem Namen die „Leopolita-Bibel”31 oder auch „die Scharffenberg-Bibel” (1561) bekannt ist. Es ist nicht sicher, wer diese katholische Bibelübersetzung verfasste. Allgemein nimmt man an ${ }^{32}$, der anonyme Text der Übersetzung wurde vom Priester Jan Nicz berichtigt und zum Druck vorbereitet, der unter einem Decknamen Jan Leopolita, das heißt Jan Lemberger, auftrat. Die sprachlich nicht einheitliche Übersetzung

${ }^{30}$ Alle im Haupttext angebrachten nl. und pl. Zitate werden von mir, Mariusz Krajcarz, ins Deutsche übersetzt. Die deutschen Entsprechungen befinden sich jeweils in den Fußnoten. „Die Schriftsteller und Übersetzer aus den reformatorischen Kreisen setzten sich zum Ziel, nicht nur den Gläubigen die Kenntnis des offenbarten Wortes Gottes in eigener Sprache zu ermöglichen, sondern sie trachteten auch mit Hilfe von Bibelübersetzungen danach - nicht ohne wesentliche Erfolge - die Anhänger für ihre Ideen zu gewinnen. In dieser Situation war auch die katholische Kirche gezwungen, ihre Zurückhaltung, und sogar die Abneigung gegen die Verbreitung der Heiligen Schrift in der polnischen Sprache zu aufzugeben und das Imprimatur den in den katholischen Kreisen inzwischen entstandenen Bibelübersetzungen und ihrem Druck zu verleihen. Die Bibel wurde zu jener Zeit zu einem Werkzeug im Kampf gegen die Ideen- und Glaubensgegner - zwischen den reformatorischen und katholischen Lagern setzte ein eigenartiges Wetteifern mit den folgenden Übersetzungen ein".

${ }^{31}$ Biblia. To jest Księgi Starego i Nowego Zakonu na polski język z pilnościq wedtug Łacińskiej Bibliej od Kościoła Krześciańskiego powszechnego przyjętej nowo wyłożona, Kraków 1561.

${ }^{32}$ Die zweite wichtige Informationsquelle über die pl. Bibelübersetzungen bildet neben dem SWB die Monographie von S. Koziara, Frazeologia biblijna w języku polskim, Kraków 2001, S. 32-39. Vgl. Angaben über die „Leopolita-Bibel”, ebd. S. 34. 
verriet wesentliche Einflüsse der gedruckten tschechischen Bibeln aus der ersten Hälfte des 16. Jh.’s ${ }^{33}$. Deshalb wurde diese Bibel ohne Begeisterung aufgenommen.

In den darauf folgenden Jahren erschienen sehr viele protestantische Übertragungen, die bis zu der Ausgabe der „Wujek-Bibel” (1599) die Übermacht über die katholischen Übersetzungen gewannen.

Die Liste wird von der „Brester Bibel”34 eröffnet, in sprachlicher Hinsicht einer der besten und schönsten altpolnischen Übertragungen ${ }^{35}$, die 1563 in Brześć Litewski veröffentlicht wurde. Der Stifter dieser Übertragung war Mikołaj Radziwiłł, der deren Ausgabe für den kalvinischen Kreis in Polen, mit dem Hauptsitz in Pinczów beauftragte. Deshalb wird sie in der onomatologischen Tradition auch die „Radziwiłł-Bibel”, „Kalvinische Bibel” oder „Pinczówer Bibel” genannt.

Die Übertragung ins Pl. wurde von einer durch die Synode zu Pinczów angestellte Gruppe von kalvinischen Übersetzern ${ }^{36}$ aus dem Hebräischen und Griechischen angefertigt, wobei die aus der lateinischen Vulgata übertragenen Apokryphen, d. h. deuterokanonischen Bücher hinzugefügt wurden. Der Haupttext wurde mit zahlreichen Kommentaren und Randbemerkungen versehen.

Nach Auffassung der damaligen Übersetzer (z. B. Jakub Wujek) sowie der zeitgenössischen Forscher (z. B. Irena Kwilecka) besitzt die Übertragung dank des reichen und sorgfältig gewählten Wortschatzes einen hohen sprachlichen Wert $^{37}$. Es war gerade die knappe, flüssige und literarisch reiche Sprache der „Brester Bibel”, die zur Folge hatte, dass einige ihrer Bücher mehrmals nachgedruckt wurden, besonders das Neue Testament (4x) und der Psalter $(1 \mathrm{x})^{38}$.

${ }^{33}$ Ebd. Von den relativ wenigen Bearbeitungen, die der Sprache und dem Übersetzungswerk der „Lemberger Bibel” gewidmet sind, wurde die breiteste Aufmerksamkeit der Forscher der lexikalischen Ebene, sowie teilweise den gewählten Bibelbüchern geschenkt. Erwähnenswert ist hier E. Belcarzowa, Charakteristik des Wortschatzes der Leopolita, [in:] Leopolita. Faksimile der Ausgabe Krakau 1561, Biblia Slavica, Serie II, Bd. 1, hrsg. von R. Olesch, H. Rothe, PaderbornMünchen-Wien-Zürich 1988, S. 37-73. Vgl. auch weitere Bibliographie von Koziara.

${ }_{34}$ Biblia święta. To jest Księgi Starego i Nowego Zakonu, własnie z Żydowskiego, Greckiego i Łacińskiego nowo na Polski język z pilnościa i wiernie wyłożone, Brześć Litewski 1563.

35 J. Godyń, ebd., S. 13.

${ }^{36}$ Zuerst in der Zusammensetzung: G. Orszacki, P. Statorjusz und J. Thenaudus aus Bourges (Frankreich), zu der sich später auch J. Szymon, J. Lubelczyk samt einigen sechzehn anderen Mitarbeitern anschlossen): Quelle: http://biblia.wortale.net/ [der Stand vom 31.12.2012].

${ }^{37}$ Vgl. S. Koziara, ebd., S. 34. Die breiteste Darstellung kultur-sprachlicher Problematik des vollen Übersetzungstextes bringt der Beitrag von I. Kwilecka, Kulturgeschichtliche und sprachliche Fragen der Übersetzung, sowie eine Reihe von Kommentaren zu der neuesten Ausgabe: Die Brester Bibel 1563. Księgi Nowego Testamentu. Kommentare, u. a. [in:] Biblia Slavica, Serie II, Bd. 2, hrsg. von H. Rothe, F. Scholz, Paderborn-München-Wien-Zürich 2001.

${ }^{38}$ Quelle: http://biblia.wortale.net/ [der Stand vom 31.12.2012]. 
Neun Jahre nach der Veröffentlichung der „Brester Bibel” entschloss sich der protestantische Kreis zu einer neuen vollständigen Bibelübersetzung - der „Nieświeżer Bibel”39 (1572) - genannt nach Nieśwież - dem Veröffentlichungsort. Ihr Verfasser war Szymon Budny, ein hervorragender Schriftsteller und Reformationsaktivist aus den arianischen Kreisen (die sog. „Polnischen Brüder"), die Urheber der ganzen Unternehmung waren.

Ursprünglich sollte die „Nieświeżer Bibel” - nach ihrem Verfasser auch als die „Budny-Bibel” bezeichnet - ein Versuch gewesen sein, den Text der „Brester Bibel” zu berichtigen, aber letztendlich entstand eine neue Übersetzung aus den Originalsprachen: dem Hebräischen und dem Griechischen.

Neben dem Haupttext befanden sich die von den Mitgläubigen zensurierten Randbemerkungen und die Fußnoten, die einige schwierigere Stellen erklärten. Kennzeichnend für die Übersetzung war die Wörtlichkeit, manchmal sogar die Buchstabentreue. Hinsichtlich des Sprachgebrauchs traten viele lexikalische Neologismen auf ${ }^{40}$, es gab aber auch Bezüge auf viele Wortschatzebenen der pl. Sprache, einschließlich die dialektalen Wortschätze ${ }^{41}$.

Erwähnenswert ist die Tatsache, dass nach der Erscheinung der ganzen „Budny-Bibel” auch ihr Neues Testament zweimal extra (1574 und 1584) herausgegeben wurde. Neben den anderen zu jener Zeit veröffentlichten protestantischen Übersetzungen von biblischen Texten bildete sie ein wichtiges Werkzeug im Kampf gegen das katholische Lager um die eigenartige ,Seelenherrschaft" über die Gläubigen ${ }^{42}$.

${ }^{39}$ Biblia. To jest księgi starego i nowego przymierza, znowu z języka Ebrejskiego, Greckiego i Łacińskiego, na Polski przełożone, Nieśwież 1572.

${ }^{40}$ Diese waren damals im Pl. unbekannt, hatten jedoch ihre Entsprechungen in den biblischen Sprachen, z. B. ofiarnik = kaptan 'Priester'; pokajanie = pokuta 'Sühne'; błożen = blogostawiony 'gebenedeit'; podsada = zasadzka 'Falle'; zapuszczenie = zastona 'Vorhang'. Quelle: http://biblia.wortale.net/ [der Stand vom 31.12.2012]. Vgl. auch andere Beispiele auch D. Bieńkowska, Polski styl biblijny, Łódź 2002, S. 60.

${ }^{41}$ Die umfangreichste Darstellung der Sprache der „Budny-Bibel”, sowie der vom Übersetzer angewandten Translationstechniken gibt der Beitrag von L. Moszyński: Zur Sprache der Bibelübersetzung Simon Budnys von 1572, [in:] Biblia to jest ksiegi Starego i Nowego Przymierza. In der Übersetzung des Simon Budny, [...] Nieśwież-Zasław 1571-1572, [in:] Die Brester Bibel 1563. Księgi Nowego Testamentu, Biblia Slavica, Serie II, Bd. 3, hrsg. von H. Rothe, F. Scholz, Paderborn-München-Wien-Zürich 1994, S. 351-414. Vgl. Bibliographie von S. Koziara, Frazeologia biblijna..., S. 34.

${ }^{42}$ Zum einen waren es das Neue Testament von Marian Czechowicz (1577), das Neue Testament von Wojciech Szmalec (1606) oder die ganze Bibel, in der Übersetzung vom Kalvinisten Marcin Janicki, deren Manuskript verloren gegangen war. Zum anderen waren es die im 16. und im 17. Jh. populär gewordenen Postillen, d. h. Sammlungen von Predigten mit einfachen Bemerkungen und Kommentaren zur Bibel (hauptsächlich zu den Evangelien) sowie die u. a. von Mikołaj Rej oder Jan Seklucjan herausgegeben Katechismen. Vgl. SWB, S. 649. 
Diese Dominanz sollte erst nach der Erscheinung der nächsten katholischen Bibel geändert werden, und zwar nach der Bibelübersetzung des Paters Jakub Wujek, die als die vollständige Heilige Schrift im Jahre 1599 in der Lazarus-Druckerei herausgegeben wurde.

Nach den Leistungen vom Pater Wujek, die im folgenden Kapitel getrennt besprochen werden, gerieten die andersgläubigen Konfessionen diesmal in die Defensive. Ihren Ehrgeiz konnten auch im Laufe der Zeit die „Brester Bibel”, und dann die „Nieświeżer Bibel” in einem stets geringerem Maße befriedigen ${ }^{43}$.

Vom Wert der Übersetzung von 1599 zeugt - wie Stansiław Koziara schreibt - zusätzlich die Tatsache, dass das protestantische Lager nach den Leistungen von Wujek ein dringendes Bedürfnis nach einer neuen Bibelübersetzung spürte ${ }^{44}$.

Die Anregung kam aus dem lutherischen Kreis, deren Ergebnis die 1632 in der Druckerei von Hünefeld herausgegebene „Danziger Bibel” ${ }^{{ }^{45}}$ war. Ihr Autor war Priester Daniel Mikołajewski, der während der Übersetzungsarbeit nicht nur die translatorischen Leistungen des protestantischen, sondern auch des katholischen Lagers ausnutzte.

Einen besonderen Platz nahm hier die „Wujek-Übersetzung” ein, auf die Mikołajewski sich häufiger berief als auf die Bibeln seiner Glaubensgenossen ${ }^{46}$.

Wie die von Koziara durchgeführte konfrontative Untersuchung der biblischen Phraseologie beweist, stimmt die „Danziger Bibel” mit der „Wujek-Bibel” öfter (57 mal) überein, als mit der „Brester Bibel” (52 mal). Die geringsten Parallellen weist der Danziger Text in diesem Falle mit der Übersetzung von Budny (33 mal) und Leopolita (48 mal) auf ${ }^{47}$.

${ }^{43}$ S. Koziara, Polszczyzna biblijna - między tradycją a wyzwaniem wspótczesności, [in:] Inspiracje chrześcijańskie..., S. 189.

${ }^{44} \mathrm{~S}$. Koziara, O frazeologizmach w polskich przekładach biblijnych. Od Biblii Wujka do Biblii Tysiaclecia, „Język Polski” LXXVII, 2-3, S. 94.

${ }^{45}$ Biblia Święta. To jest księgi Starego i Nowego Przymierza z Żydowskiego i Greckiego Języka na Polski pilnie i wiernie przettumaczone, Gdańsk 1632.

${ }^{46}$ Vgl. M. Kossowska, Biblia w języku polskim, Bd. I, Poznań 1968, S. 349-354. Als Exemplifizierung können hier die von S. Koziara miteinander verglichenen phraseologischen Konstruktionen sein, wovon über zwei Drittel eine analoge Form in beiden Texten aufweist. So wurden beispielsweise in der „Danziger Bibel” die Wendungen oddać ducha (J 19,30) und rozdzierać szaty (Mt 26,65) nach der „Wujek-Bibel” und nicht nach der „Brester Bibel” verwendet, wo entsprechend poddać ducha und rozdzierać odzienie vorkamen. S. Koziara, Frazeologia biblijna...

${ }^{47}$ Es ist jedoch schwierig nachzuweisen, welche von den aufgeführten Wortverbindungen ihren Ursprung in der Danziger Übersetzung haben. Das kann ein Beweis dafür sein, dass Mikołajewski in diesem Falle auf die phraseologischen Einheiten mit dem stabil gewordenen 
Der Text der Danziger Bibelübersetzung gilt als ziemlich wortwörtlich, er verfügt auch über keine Erläuterungen und Randbemerkungen ${ }^{48}$.

Anfänglich wurde die Danziger Bibel u. a. wegen der allzu vielen Abweichungen von der Brester Ausgabe kritisiert ${ }^{49}$, mit der Zeit wurde sie allmählich akzeptiert, und schließlich anerkannt als ein für alle evangelischen Glaubensgemeinschaften in Polen verbindlicher Text, so dass die pl. Protestanten über dreihundert Jahre kein Bedürfnis auf die neue Bibelübersetzung mehr hatten ${ }^{50}$.

Die Danziger Bibel wurde oftmals im In- und im Ausland neu gedruckt (über 20 volle Ausgaben). Sie errang unter den pl. Protestanten eine solche Popularität, wie die „Wujek-Bibel” unter den Katholiken, die - Michał Wojciechowski's Meinung nach - die beste altpolnische Übertragung der Heiligen Schrift war, die genauer und getreuer von allen bisher besprochenen Bibelübersetzungen war ${ }^{51}$.

\section{Zwei prägnanteste Bibeln - die „Staatenbibel” und die „Wujek-Bibel”}

\subsection{Die „Staatenbibel” 52 - die Bibelübersetzung von 1637}

\subsubsection{Vorgeschichte und Zielsetzungen}

Obwohl sich die 1562 erschienene „Deux-aes-Bibel” unter den nl. Reformierten einer großen Popularität erfreute, zeigten die Kalvinisten auf den Landessynoden ein immer stärkeres Verlangen danach, die nl. Übersetzung der ganzen Bibel, insbesondere des Alten Testaments, direkt aus den Originalsprachen zu besitzen.

Derartige Übersetzungen wurden Gelehrten und Theologen in Auftrag gegeben, unter anderem Philips Marnix von Sint-Aldegonde (1540-1598), der wegen seines frühen Todes nur das Buch Genesis übersetzen konnte.

\footnotetext{
Status anknüpfte, wobei er dadurch zur Stärkung ihrer stilistischen Identität beitrug. Vgl. S. Koziara, Rola Biblii w ksztaltowaniu stylowej odrębności polszczyzny biblijnej, [in:] „Myśl Protestancka" 2002, 3-4, S. 72-73.

48 S. Koziara, Frazeologia biblijna..., S. 36.

${ }^{49}$ Z. Nowak, Biblia gdańska jako przedsięwzięcie typograficzne, „Myśl Protestancka” 2002, 3-4, S. 65.

${ }^{50}$ S. Koziara, O frazeologizmach..., S. 94.

${ }^{51}$ SWB, S. 652.

${ }^{52}$ Biblia, dat is de gantsche H. Schrifture, vervattende alle de Canonijcke Boecken des Ouden en des Nieuwen Testaments, Leiden 1637.
} 
Als auf der Dordrechter Synode (1618-1619) die Lehre der Protestanten erneut festgelegt wurde, beschloss man bei dieser Gelegenheit auch, eine neue Bibelübersetzung anfertigen zu lassen. Ein Jahr danach wurde hierfür von den Generalstaaten (Teilen des Staatenbundes) der Auftrag erteilt, der auch die Finanzierung der ganzen Unternehmung ermöglichte ${ }^{53}$.

Die „Staatenbibel” sollte eine theologisch begründete Übersetzung mit wissenschaftlichen Ambitionen sein, wobei das Alte Testament aus dem Hebräischen und das Neue Testament aus dem Griechischen und Aramäischen ins Nl. übersetzt werden sollte. Außerdem sollte sie in einer Sprache geschrieben sein, die von jedem Niederländer verstanden und akzeptiert werden konnte ${ }^{54}$.

\subsubsection{Entstehung der „Staatenbibel”}

Um eine allgemein akzeptable Sprache zu erreichen, sollten Übersetzer und Revisoren aus allen Teilen des Landes zusammenarbeiten. Unter ihnen waren zwei Friesen, zwei Ostflamen, ein Seeländer und ein Holländer. Sie zogen in die Universitätsstadt Leiden ein, wo sie die nötige wissenschaftliche Hilfe bekommen konnten und wo ihnen die Bibliothek mit allen zugänglichen Bibelübersetzungen, Kommentaren und Wörterbüchern zur Verfügung stand ${ }^{55}$. Die Übersetzer versuchten zunächst, Übereinstimmungen zwischen den verschiedenen Dialekten zu finden und Kompromisse in Rechtschreibung, Grammatik und Wortgebrauch zu erarbeiten. Die Übersetzung wurde im Nachhinein von den Revisoren berichtigt, deren jeweils zwei von jeder Landessynode berufen wurden. Der eine war für das Alte Testament und der andere für das Neue Testament zuständig, „ook wat de naleving betrof van een reeks richtlijnen voor het taalgebruik, opgesteld door de Dordrechtse synode" 56 .

Nach fast zwanzigjährigen Übersetzungsarbeiten wurde die „Staatenbibel” veröffentlicht. Die erste Ausgabe erschien 1637 im Verlag Paulus Aertsz. van

${ }^{53}$ Vgl. J.W. de Vries, R. Willemyns, P. Burger, Het verhaal van een taal. Negen eeuwen Nederlands, Amsterdam 1993, S. 83.

${ }^{54}$ Ebd.

${ }^{55}$ J. van Delden, ebd., S. 42-43.

56, ,...] auch, wenn es um die Befolgung einer Reihe von Richtlinien für den Sprachgebrauch ging, die durch die Dordrechter Synode abgefasst waren". Ebd., S. 43. Als Revisoren arbeitete aus jedem Landesteil je ein Sachkundiger, mit Ausnahme von Drente und Oberijssel, die sich entschuldigen ließen, weil sie niemanden mit der nötigen theologischen und sprachwissenschaftlichen Ausbildung auffinden konnten. Auf diese Weise fanden die östlichen Dialekte in der Übersetzung kaum ihren Niederschlag. Den größten Einfluss hatten die südlichen Dialekte (vor allem die in Brabant gebräuchliche Mundart) auf die Sprache der Bibel, da sie durch Schriften schon bekannt waren und von den (meist wohlhabenden) Immigranten gesprochen wurden. Außerdem klangen die Wörter für nordniederländische Ohren feierlich. Mehr dazu in J.W. de Vries, R. Willemyns, P. Burger, ebd. und M. Van der Waal, ebd. 
Ravensteyn in Leiden, ,welke tekst weldra niet alleen bij de gereformeerden, maar ook bij remonstranten en de meeste doopsgezinden gezag verwierf'57.

Als Theologen und Sachkundige der östlichen und klassischen Sprachen hatten die Übersetzer und Revisoren ein grandioses Werk geschaffen. Ihre Übersetzung stand auf einem sehr hohen wissenschaftlichen Niveau. Diese Auffassung vertritt unter anderem C.C. de Bruin, der die Resultate dieser translatorischen Unternehmung auf die folgende Art und Weise zusammenfasst: ,Zonder iets van hun zelfstandigheid te laten varen, maar toch gaarne luisterend naar hun voorgangers en met bezonnen oordeel eclectisch te werk te gaan bij de raadpleging van hun wetenschappelijk apparaat wisten zij een vertaling tot stand te brengen, die geheel beantwoorde aan de wetenschappelijke eischen van hun tijd"58. Dabei schöpften sie aus einer reichen Bibeltradition, was auch die Autorinnen des Bijbel lexicon unterstreichen. „De ingeburgerde Liesveldt - en Deux-Aesbijbel werd daarbij recht gedaan, zodat de zuidelijke inslag en de vernieuwingen onder invloed van de Luthervertaling ook in de taal van de Statenbijbel kenbaar werden" 59 .

\subsubsection{Die Sprache der „Staatenbibel”}

Im Folgenden sind einzelne Punkte dialektaler Unterschiede in den Bereichen Grammatik, Rechtschreibung und Wortgebrauch angeführt, die von den Übersetzern besprochen und über die schließlich bestimmte Entscheidungen getroffen wurden ${ }^{60}$. Auf Vollständigkeit wird bei dieser Darstellung kein Anspruch erhoben.

Im Bereich der Grammatik.

Man verwendete beispielsweise

- ghi (ghy) als Ansprechform für die 2.P.Sg. und 2.P.P1., statt des in früheren Bibeln gebrauchten, aber inzwischen veralteten $d u$, weil $d u$ damals als

57, ,[...] und diese Übersetzung bald nicht nur bei den Reformierten, sondern auch bei den Remonstranten (= Arminianern) und den meisten Taufgesinnten Ansehen erwarb". J. van Delden, ebd.

58 „Ohne etwas von ihrer Eigenständigkeit aufzugeben, hörten sie dennoch gern ihren Vorgängern zu, gingen mit besonnenem Urteil auswählend an die Arbeit und indem sie ihren wissenschaftlichen Apparat zu Rate zogen, vermochten sie es eine Übersetzung zustande zu bringen, die den wissenschaftlichen Forderungen ihrer Zeit völlig entsprach". Vgl. C.C. de Bruin, De Statenbijbel en zijn voorgangers, Leiden 1937, S. 296. Siehe auch J. van Delden, ebd., S. 50.

59 „Der eingebürgerten 'Liesveldt'- und 'Deux-Aesbibel' wurde dabei gerecht getan, so dass der südliche Einschlag und die Neuerungen unter dem Einfluss der Lutherübersetzung auch in der Sprache der 'Staatenbibel' erkennbar wurden”. K. van Dalen-Oskam, M. Mooijaart, ebd., Einleitung, S. 17.

${ }^{60}$ Die typischen Beispiele der Änderungen im Bereich der Grammatik, Rechtschreibung und Wortgebrauch wurden den Werken von J. van Delden, ebd., S. 55-62 und J.W. de Vries, R. Willemyns, P. Burger, ebd., S. 83-85 entnommen. 
eine unhöfliche Form angesehen wurde. Ghi wurde dagegen als Ausdruck von Respekt und Höflichkeit verwendet;

- keine Konjugationsendungen in der 1. und 3.P.Sg. Beispielsweise wurden das -e in ik hore, ik geve, ik mene... und das $-t$ in hij wilt... konsequent vermieden;

- Kasusendungen, wie die Grammatiker sie vorschrieben (z. B. im 5. Gebot: Eert uwen vader ende uwe moeder „Ehrt euren Vater und eure Mutter”);

- mij ,mich” als Akkusativform von $i k$,,ich”. Die bisherige holländische Form „mijn” wurde verworfen, da sie als ein in den unteren sozialen Schichten üblicher Ausdruck angesehen wurde;

- zich „sich” als reflexives Fürwort unter dem Einfluss der östlichen Dialekte. Auch wurden die ursprünglichen Reflexivpronomina hem und haer wegen der Möglichkeit des Missverständnisses verworfen (z. B. hij sloeg hem konnte „er schlug ihn” oder ,er schlug sich” bedeuten).

Außerdem wurden Bedeutungsunterschiede z. B. zwischen worden/werden; liggen/leggen; denken/dunken berücksichtigt. Von den Doppelformen: dacht/docht; bracht/brocht wurden die ersten bevorzugt.

Im Bereich der Rechtschreibung.

Man entschied sich

- in den meisten Fällen für das westliche <ee $>$, statt des östlichen <ae $>$

(z. B. rechtveerdig statt rechtvaerdig ,gerecht”; aber aerde „Erde”...);

- für das nördliche $<\mathrm{g}>$ statt des südlichen $<\mathrm{j}>$ (z. B. gunste statt jonste „Gunst");

- für das südliche -ken als Diminutivsuffix, statt des nördlichen -je, der heute gebräuchlichen Endung;

- für $<\mathrm{a}>$ in offenen und $<\mathrm{ae}>$ in geschlossenen Silben (nur die a-Rechtschreibung war konsequent geregelt);

- für die veralterte Konjunktion ende, statt en, die heute in Gebrauch ist;

- für eine Unterscheidung von Homonymen durch unterschiedliche Schreibweise, z. B. das Possessivpronomen sijn „sein” und das Verb zijn „sein”;

- für nominale Formen mit der Endung auf - $e$, wie Heere „Herr”, und Formen auf -ije, -isse, -inge (südniederländischer Einfluss) ${ }^{61}$.

In späteren Ausgaben der „Staatenbibel” wurde die Schreibweise mehrmals an neuere Anforderungen der Zeit angepasst, aber - wie J. Van Delden zu Recht bemerkt - „de spellingopvattingen van de translateurs en de reviseurs hebben voor de schrijfwijze van onze taal geen gevolgen gehad die de bijbellezer van nu direkt raken"62.

${ }^{61}$ Vgl. J.W. de Vries, R. Willemyns, P. Burger, ebd., S. 89.

62 ,[...] die Rechtschreibauffassungen der Übersetzer und Revisoren haben für die Schreibweise unserer Sprache keine Folgen gehabt, die den Bibelleser von heute direkt betreffen". J. van Delden, ebd., S. 62. 
Im Bereich des Wortgebrauchs.

Man ersetzte veraltete und veralternde Wörter, wie z. B. zich genéren durch eten „essen”, (3. Mose: 17), zweer durch schoonvader „Schwiegervater” (Richt 1:16), deerne durch jonge vrouw ,junge Frau” (Ruth 2:5) oder dochter „Tochter” (2. Kön 14:9), ondergronden durch onderzoeken ,erforschen, prüfen” (Klagel 3:40), die reden durch dit woord „dieses Wort” (Mark 8:32);

Man bildete neue Wörter und Ausdrücke,

- Neologismen: z. B. ter elfder ure „zur elften Stunde”, een steen des aanstoots ,ein Stein des Anstoßes”;

- Hebraismen: z. B. het boek der boeken „das Buch der Bücher”, zondebok „Sündenbock”, slachtoffer „Schlachtopfer”;

- die direkt aus dem Griechischen übersetzt wurden: z. B. zich niet onbetuigd laten „mitmachen, nicht zurückbleiben”;

Man behielt jedoch im begrenzten Umfang

- Germanismen bei: z. B. gewoonheid statt gewoonte „Gewohnheit” (Richt 11:39); krijgen statt oorlog voeren „Krieg führen” (Richt 1:3), armgesnijde statt de sieraden om zijn arm „Armgeschmeide” (2. Sam 1:10);

- viele schon eingebürgerte Lehnwörter. In der „Staatenbibel” sind unter anderem erhalten geblieben: 'Nochthans heeft hij mij een eeuwig verbond gesteld, dat in alles wèl geordineerd en bewaard is' ,...geordnet...” (2. Sam 23:5); 'We gijlieden tegen de koning rebelleren' ,....abfallen” (Neh 2:19); 'En de HERE God had de mens geformeerd uit het stof der aarde' ,...machte..." (1. Mose 2:7); 'Dies wankelen alle fundamenten der aarde' ,...Grundfesten..." (Ps 82:5); 'Al ware het, dat ik de gave der 'profetie had' „...weissagen..." (1. Kor. 13:2).

Als die größte translatorische Unternehmung ihrer Zeit übte die „Staatenbibel" ebenfalls einen großen Einfluss auf die Gestaltung des Wortschatzes des gegenwärtigen N1. aus.

Viele feste Wörter und Wortgruppen, die zwar schon in der „LiesveldtBibel” oder der „Deux-Aes-Bibel” anzutreffen waren, waren erst durch die Vermittlung der „Staatenbibel” populär geworden ${ }^{63}$. Auch die heutigen Bibelphraseme, die erst in der „Staatenbibel” (1637) ihren Ursprung finden, wie z. B.: de beker of drinkbeker aan zich voorbij laten gaan, uit den boze, oud en der dagen zat, op twee gedachten hinken, de geest geven, in het zweet zijns aanschijns etc. sind dauerhaft in den Kanon der biblischen Phraseologie des N1. eingegangen.

${ }^{63}$ Die „Liesveldt-Bibel” (1526): het stof van zijn voeten schudden, een teken aan de wand, ivoren toren [...]. Die „Deux-aes-Bibel” (1562): paarlen voor de zwijnen werpen, als een dief in de nacht, gewogen en te licht bevonden [...]. Beispiele aus Bijbels lexicon von K. van DalenOskam, M. Mooijaart, ebd. 
Zusammenfassend kann man nach dem Autor von Spreekwoorden en zegswijzen uit de bijbel wiederholen: „Nieuwe woorden zijn door de bijbel geïntroduceerd, oude voor uitsterven behoed en opnieuw tot leven gewekt. Diverse eigennamen, uitdrukkingen, zegswijzen spreekwoorden vinden oorsprong in de bijbel (soms tot grote verrassing van de taalgebruiker), of zijn voornamelijk door de bijbel bekend geworden of gebleven" ${ }^{64}$.

\subsubsection{Die Rolle der „Staatenbibel”}

Das größte Verdienst der „Staatenbibel” liegt in dem Versuch, durch die Zusammenarbeit von Angehörigen verschiedener Dialektgruppen eine gemeinschaftliche Basis für eine einheitliche nl. Sprache zu schaffen. Die Rolle dieser Bibel lässt sich mit derjenigen vergleichen, welche die Lutherbibel bei der Entwicklung der allgemeinen deutschen Sprache spielte.

Die Sprache der „Staatenbibel” wurde von den Niederländern bereits im 17. Jahrhundert als veraltet empfunden, und es entstand in dieser Zeit auch eine Abneigung gegen das südliche Niederländisch. Die Bibel wurde aber trotzdem nicht revidiert, da sie gerade durch ihren veralteten Sprachgebrauch und den komplizierten Satzbau das Gefühl einer heiligen Schrift hervorrufen konnte. Zugleich wurde die „Staatenbibel” auch als Vorbild für guten Sprachgebrauch angesehen.

Die „Staatenbibel” nahm bei den kalvinistischen Familien einen wichtigen Platz ein. Täglich nach der Mahlzeit wurde daraus vorgelesen. In der Schule wurde sie im Religionsunterricht verwendet. An Sonn- und Festtagen wurde die Bibel in der Kirche ausgelegt. Sie war somit das meist gelesene Buch der protestantischen nl. Bevölkerung ${ }^{65}$. Die Autorinnen des Bibel-Lexikons bemerken zu Recht: „Door veelvuldig en langdurig gebruik in kerk, school en gezin, juist in een periode dat de standaardtaal zich ging vormen, heeft deze vertaling een stempel op het algemene Nederlands gedrukt" ${ }^{\prime 66}$.

64 „Neue Wörter sind durch die Bibel eingeführt, andere vor dem Aussterben bewahrt und neu belebt worden. Verschiedene Eigennamen, Ausdrücke, Redensarten und Sprichwörter haben ihren Ursprung in der Bibel (manchmal zur großen Überraschung des Sprachverwenders) oder sie sind hauptsächlich durch die Bibel bekannt geworden oder geblieben". J. van Delden, ebd., S. 62 .

${ }^{65}$ Dies bestätigt unter anderem P. Kat Pzn. in seiner Bearbeitung Bijbelsche uitdrukkingen en spreekwijzen in onze taal, Zutphen 1926, S. 30.

${ }^{66}$ „Durch einen vielseitigen und lang anhaltenden Gebrauch in Kirche, Schule und Familie, gerade in einer Zeitepoche, da sich die Standardsprache herausbildete, hat diese Übersetzung dem allgemeinen Niederländisch ihren Stempel aufgedrückt”. K. van Dalen-Oskam, M. Mooijaart, ebd., S. 17. 


\subsubsection{Reaktion auf die „Staatenbibel”}

Von verschiedenen protestantischen Gruppierungen hielten nach der Erscheinung der „Staatenbibel” allein die Lutheraner an der eigenen Übersetzung fest. Bis 1648 gebrauchten sie die „Biestkens-Bibel” und dann die neue nl. Lutherbibel, die von Adolf Visscher, dem lutherischen Pastor aus Amsterdam, übersetzt wurde. Diese Bibel blieb bis 1951 die Bibel der Lutheraner, auch wenn sie im Laufe der Jahre verschiedenen Revisionen unterzogen wurde ${ }^{67}$.

Die „Staatenbibel” ist bis auf den heutigen Tag in Gebrauch, hauptsächlich jedoch bei den evangelisch-reformierten Kirchen und dem rechten Flügel der Orthodoxie.

Im Jahre 1943 wurde auf der Grundlage der „Staatenbibel” die Übersetzung der „Friesischen Bibel” angefertigt.

\subsubsection{Revidierte Ausgaben}

Schon seit dem 18. Jh. gab es Versuche, den Text der „Staatenbibel” zu modernisieren. Revidiert wurden vor allem Rechtschreibung und Wortwahl. Johannes van der Palm, Hochschullehrer für orientalische Sprachen in Leiden, fertigte in den Jahren 1818-1830 eine an die „Staatenbibel” anknüpfende, jedoch viel zugänglichere Übersetzung an. Diese neue und revidierte Übersetzung fand jedoch nur geringen Beifall.

An dieser Stelle ist die Neuausgabe der „Staatenbibel” durch die Evangelisch-Reformierte Bibelstiftung zu erwähnen. Diese Ausgabe strebt danach, der ursprünglichen Ausgabe möglichst nahe zu kommen, wobei regelmäßig auf die sog. „Ravesteyn-Bibel” aus 1657 verwiesen wird. Damit befand sich diese Übersetzung im Gegensatz zu der sog. „Jongbloed”-Ausgabe, die im Laufe der Jahrhunderte zahlreichen nötigen sprachlichen Korrekturen angepasst wurde. Die „Jongbloed”-Ausgabe ist heutzutage von allen Varianten der „Staatenbibel” die meist gebräuchliche Ausgabe in den Niederlanden. „Jongbloed" bezieht sich in diesem Kontext auf das Verlagshaus Jongbloed GmbH in Heerenveen.

Eine neuere Modernisierung der „Staatenbibel” ist die sog. ,Tukker”Ausgabe, die im Jahre 1977 von der Niederländischen Bibelgesellschaft herausgegeben wurde. Der Text wurde von Prof. Wouter Leendert Tukker revidiert.

In Dezember 2010 ist einer Gruppe von zwanzig Theologen aus den konservativen Kreisen gelungen, den revidierten Text der „Staatenbibel” neu zu veröffentlichen. Sie vertraten nämlich den Standpunkt, dass der Text der ursprünglichen „Staatenbibel” von den meisten Jugendlichen nicht mehr verstan-

\footnotetext{
${ }^{67}$ Gefunden bei www.nl.wikipedia.org/wiki/Bijbelvertaling [der Stand vom 31.12.2012].
} 
den war und deshalb modernisiert werden musste. Sie waren auch der Meinung, dass der Text der Neuen Bibelübersetzung aus 2004 zu progressiv war $^{68}$.

\subsection{Die „Wujek-Bibel” ${ }^{69}$ - die Bibelübersetzung von 1599}

\subsubsection{Vorgeschichte und Zielsetzungen}

Die zweite Hälfte des 16. Jh.'s war eine Periode der scharfen Polemik der katholischen Kirche gegen den Protestantismus. In diesem Meinungsstreit bildete die Bibel, ihre Übertragung und Interpretation eines der wichtigsten Themen konfessioneller Auseinadersetzungen.

Die Übersetzung der heiligen Schrift, die dem Ordenspriester Jakub Wujek durch den Jesuitenorden im Jahre 1585 in Auftrag gegeben wurde, sollte eine Antwort der Katholiken auf die in jener Zeit wesentlichen translatorischen Leistungen des protestantischen Lagers sein. Denn als Wujek sich an die Übersetzungsarbeit machte, verfügten die Protestanten in Polen schon über zwei volle Bibelübersetzungen, um nur die kalvinische „Brester Bibel” (1563), oder die arianische „Nieświeżer Bibel” (1572) zu nennen, die mit eigenen, im protestantischen Geist gehaltenen Erklärungen versehen waren. Die einzige gedruckte katholische Übersetzung, die sog. „Leopolita-Bibel” (1561) konnte sich mit protestantischen Übersetzungen in sprachlicher und sachlicher Hinsicht nicht gleichmessen, vorwiegend aus Mangel an entsprechenden Kommentaren.

Es gab also ein dringendes Bedürfnis, den Katholiken sowohl einen Text der Heiligen Schrift als auch eine entsprechende Bibelinterpretation zur Verfügung zu stellen, die eine Antwort auf heterodoxe Kommentare und eine musterhafte Auslegung der Kirchenlehre sein könnten ${ }^{70}$.

Aber andererseits bestand - wie man weiß - das 16. Jh. in Polen nicht nur aus der Reformationszeit, also der Periode des religiösen Kampfes und eines

${ }^{68}$ Ein weiteres Argument für diese neu überarbeitete „Staatenbibel” (und auch ein erheblicher Punkt der Kritik) ist, dass die „Staatenbibel” aus einer Reihe von Handschriften als Textus Receptus für das Neue Testament bekannt ist. Die neueren Übersetzungen verwenden den ,kritischen Text", der u.a. in der Novum Testamentum Graece von Nestle-Aland zu finden ist. Der Textus Receptus ist eine im 16. Jahrhundert von Erasmus produzierte Variante des byzantinischen Textes. Dieser Text enthält viel Textpassagen, die in den älteren biblischen Handschriften, die uns jetzt verfügbar sind, nicht vorhanden sind und vermutlich in den frühen Mittelalter zwischen den Text geraten sind. Viele konservative Christen glauben, es sei wichtig, dass das Wort Gottes einheitlich sein soll und deshalb halten sie sich an die ursprünglich verwendeten Manuskripten. http://nl.wikipedia.org/wiki/Herziene_Statenvertaling [der Stand vom 31.12.2012].

${ }^{69}$ Biblia to jest Księgi Starego i Nowego Testamentu, wedtug tacińskiego przekładu starego w Kościele powszechnym przyjętego, na Polski język znowu z pilnościa przetożone z dokładaniem textu Żydowskiego i Greckiego [...], Kraków 1599.

${ }^{70}$ Biblia w przekładzie księdza Jakuba Wujka z 1599 r. Transkrypcja typu „B” oryginalnego tekstu z XVI w. i wstępy ks. Janusz Frankowski, Warszawa 1999, S. XVIII. 
erhöhten Bedarfs nach der Bibel, sondern es war auch der Humanismus, also die Öffnung auf die Kultur der Antike, dessen Ideen die Bibelübersetzungen beeinflussten.

Diese Ideen verursachten, dass die Bibelübersetzer nicht nur nach dem Text der Vulgata griffen, sondern auch nach den griechischen und hebräischen Texten. Sie begannen auch andere als die von der Vulgata stammenden Übersetzungen aus dem Lateinischen zu berücksichtigen ${ }^{71}$.

\subsection{2. Übersetzungsmethode}

Eben in einer solchen Zeit entschloss sich der Priester Jakub Wujek zu diesem translatorischen Lebenswerk. „A posiadał on - wie Janusz Frankowski ${ }^{72}$ schreibt - wszystkie potrzebne do takiego dzieła kwalifikacje. Po pierwsze był w owym czasie z pewnością jednym z najbardziej wykształconych w Polsce teologów i człowiekiem czynu. Po drugie, odpowiadał humanistycznemu ideałowi uczonego z początku XVI wieku: znał bardzo dobrze łacinę i grecki, prawdopodobnie opanował też dobrze język hebrajski [... "'73. Neben den biblischen und klassischen Sprachen besaß er auch fließende Deutschkenntnisse und zeigte ein ungewöhnliches Schreibtalent in der Muttersprache. Er war u. a. Verfasser von zwei Postillen ${ }^{74}$.

Als Exeget, Philologe und Übersetzer kannte Jakub Wujek sich außerdem sowohl im Bereich der älteren als auch der zeitgenössischen Übersetzungen der Heiligen Schrift sehr gut aus. Deswegen hatte er ein klares, modernes Übersetzungskonzept, das den ihm gestellten Anforderungen der Epoche, in der er lebte, entsprach. Priester Frankowski erklärt: ,Wprawdzie tłumaczył z Wulgaty, czyli tekstu łacińskiego - co było krokiem wstecz w wieku, w którym humaniści odkryli wartość tekstów oryginalnych - ale tego żądał od niego Kościół, broniący swego wiekowego dziedzictwa i szukający elementów spajających. Ks. Wujek nadrabiał tę konieczność tłumaczenia z łaciny, zwłaszcza jeśli chodzi o Nowy Testament, ciągłym kontaktem z tekstem greckim"75.

71 R. Bura, Polska, czeska i tużycka frazeologia pochodzenia biblijnego, Kraków 2003, S. 15.

72 Biblia w przekładzie..., S. XVIII.

73 „Und er besaß alle zu diesem Werk nötigen Qualifikationen. Erstens war er damals gewiss einer der in Polen meist ausgebildeten Theologen und ein Mensch der Tat. Zweitens entsprach er dem humanistischen Ideal eines Gelehrten aus dem Anfang des 16 Jh.'s: er kannte sehr gut Latein und Griechisch, wahrscheinlich beherrschte er auch gut Hebräisch [...]”. Ebd.

74 Ebd.

75 „Zwar übersetzte er aus der Vulgata, also dem lateinischen Text - was ein Schritt rückwärts war, im Zeitalter, in dem die Humanisten den Wert der originalen Texte entdeckt hatten aber dies verlangte die Kirche von ihm, die ihr jahrhundertlanges Erbe verteidigte und nach verbindenden Elementen suchte. Die Notwendigkeit, aus dem Lateinischen zu übersetzen, holte J. Wujek durch einen ständigen Kontakt mit dem griechischen Text nach, besonders bei der Übertragung des Neues Testaments". Ebd. 
Er sah nämlich ein, - wie Renata Bura ${ }^{76}$ hinzufügt - dass ,[...] grecki język do prawego wykładania i rozumienia Pisma Św. w Nowym Testamencie jest nie tylko barzo pożyteczny, ale i potrzebny" "77.

Nach der Auffassung von Wujek war es nämlich notwendig, den griechischen Text zu berücksichtigen. Dies tat er - wie er selbst erklärte - aus zwei Gründen. Einerseits um des Lesers willen, damit er die Heilige Schrift besser verstehen und gleichzeitig zwei Übersetzungen vor den Augen haben könnte „aby się samą rzeczą pokazało, że w tekście greckim jest daleko więcej przysad i omyłek, aniżeli łacińskim, co każdy snadnie pozna oba teksty znosząc" Andererseits bediente Wujek sich des griechischen Textes um seinetwillen als Übersetzer und Exeget, ,abych się w słowach łacińskich wątpliwych kędy nie potknąwszy w wykładzie nie zbłądził"79.

Die Übersetzung soll möglichst getreu, aber auch verständlich gewesen sein. Deshalb löste sich Wujek von der starren Lehnübersetzung und war bemüht, den Sinn wiederzugeben ${ }^{80}$.

\subsubsection{Entstehungsprozess}

Die ganze Übersetzung, dem er sich fünfzehn Jahre mit vollem Engagement gewidmet hatte, entstand in Etappen. Die erste Frucht der translatorischen Bemühungen Wujek's war die Übersetzung des Neuen Testaments, die 1593 veröffentlicht wurde, danach die des Psalmenbuches: „Psałterz Dawidów" aus 1594.

Der volle Text der Bibelübersetzung war schon früher fertig, und zwar noch zu Lebzeiten des Verfassers, er erschien aber im Druck erst 1599, also zwei Jahre nach seinem Tode. Viel Zeit nahm die Zensorenkommission in Anspruch, um das Werk durchzusehen und zum Druck freizugeben.

Die Zensoren waren der Auffassung, dass Wujek allzu frei übersetzte und zu weit von der Vulgata abwich. Es wurde eine sehr detaillierte Revision der Übersetzung durchgeführt. Die Revision änderte in einem großen Maße den Charakter der ursprünglichen Übersetzung. Wujek sorgte dafür, dass jeder Satz

76 Zitiert nach R. Bura, ebd., S. 15.

77, ,...] das Griechische ist für die richtige Auslegung und das Verständnis der Heiligen Schrift im Neuen Testament nicht nur sehr nützlich, aber auch notwendig”. Ebd.

$78, \ldots[. .$.$] damit sich dadurch erweisen würde, dass es im griechischen Text viel mehr Über-$ treibung und Fehler gibt, als im lateinischen, was sofort erkennbar ist, wenn man beide Texte miteinander vergleicht". Ebd.

79, ,...] dass ich mich bei zweifelhaften lateinischen Wörtern nirgendwo Fehler machen und bei der Auslegung nicht irren würde". Ebd.

${ }^{80}$ Vgl. J. Frankowski, ebd. 
verständlich war. Die Revisoren ${ }^{81}$ bevorzugte eine mechanische Übertragung, wobei man hauptsächlich darauf achtete, dass sie nur den Wortlaut der Vulgata wiedergab.

Dass die zensurierte Ausgabe in einem wesentlichen Grad die WujekÜbersetzung an den Text der Vulgata annäherte, geschah - nach Meinung von Stanisław Koziara - zum Schaden vieler Bemühungen des Verfassers um die Übersetzung zu verpolnischen und in der Übersetzungsarbeit auch die übrigen Originalsprachen $\mathrm{zu}$ berücksichtigen ${ }^{82}$.

Eine strengere Meinung über die Berichtigungen, die durch die Jesuitenkommission gemacht wurden, äußert Janina Czerniatowicz ${ }^{83}$, indem sie das Folgende feststellt: „Krzywda dla pracy Wujka i dla polskiego dzieła”84.

Eine andere Auffassung vertritt der zuvor erwähnte Frankowski, der an dem Text der Bibel von 1599 zwanzig Jahre gearbeitet hat, um sie im Jahre 1999 wieder herauszugeben. Er ist der Meinung, dass die von der Kommission eingeführten Änderungen sehr oft richtig waren, wenn es beispielsweise um poetische Texte ging. Die Revisoren hatten eine ursprünglichere und zugleich knappere Bedeutung von Zeilen wiederhergestellt, was der ganzen Übersetzung einen poetischen Charakter verlieh ${ }^{85}$.

Priester Frankowski behauptet auch: „Ponadto Wujek używał wprawdzie żywego, ale niekiedy zbyt kolokwialnego staropolskiego języka. Rewizorzy usunęli w dużej mierze tę potoczność oraz formy zbliżone do gwarowych i wprowadzili język 'wyższy’ należący do głównego nurtu języka polskiego"86. Doch in dieser Hinsicht - wie Renata Bura ${ }^{87}$ mit Recht bemerkt - ,język Wujka

${ }^{81}$ An der Vorbereitung der „Wujek-Bibel” zum Druck arbeiteten fünf Kommissionsmitglieder - Sprachwissenschaftler: (J. Rab, J. Brant, M. Łaszcz, A. Radzimiński) unter Führung von S. Grodzicki, einem der Ordensmitbrüder von Wujek, dem Gegner seiner Übersetzungsmethode. Vgl. J. Sobczykowa, O językoznawczej wartości komentarza w Biblii Jakuba Wujka, [in:] Inspiracje chrześcijańskie..., S. 263. Auch S. Koziara, Frazeologia biblijna..., S. 34.

${ }^{82}$ S. Koziara, Frazeologia biblijna.., S. 34.

${ }^{83} \mathrm{Vgl}$. J. Czerniatowicz, Niektóre problemy naukowe grecystyki w pracach biblistów polskich XVI i XVII w., Wrocław 1969, S. 76.

${ }^{84}$ „Ein Unrecht für das Werk von Wujek und für sein polnisches Werk”. Ebd.

${ }^{85}$ Nach der Anschicht von J. Frankowski: „Wujek, wybitny prozaik, nie miał wyczucia poetyckiego" (Wujek, ein hervorragender Prosaist, hatte keinen Sinn für Poesie - Übers. M.K.). Diese Meinung hat er im Interview geäußert: Cztery wieki Biblii Wujka. Rozmowa z księdzem profesorem Januszem Frankowskim, autorem nowego opracowania tekstu Biblii Jakuba Wujka, „Życie” 1999, 83 (9.04.1999), Beilage: „Życie z książkami”, S. III.

${ }^{86}$ „Außerdem bediente Wujek sich zwar einer lebendigen, aber manchmal einer allzu kolloquialen Sprache. Die Revisoren beseitigten größtenteils diese Umgangssprachlichkeit sowie die sich dem Dialekt angenäherten Formen und führten eine «erhabenere», zum Hauptstrom des Pl. gehörende Sprache ein". Vgl. Biblia w przektadzie..., S. XIX.

${ }^{87}$ R. Bura, ebd., S. 18. 
bliski jest oryginałowi greckiemu, który zapisany jest w tzw. koine [...], czyli dialekcie powszechnym"88.

Abgesehen von den Teilverdiensten der Revisoren leistete Jakub Wujek eine vorzügliche Arbeit, die zur Folge hatte, dass seine Bibel ihre Aktualität und Funktionalität bis in die Mitte des 20. Jahrhunderts aufrechterhalten konnte ${ }^{89}$. Diese Auffassung bestätigen auch die bisherigen fundierten Untersuchungen im Bereich der Phraseologie, die die eigenen und zensurierten Bibelübersetzungen von Wujek miteinander vergleichen ${ }^{90}$.

\subsubsection{Aufbau und Sprache}

Die Bibel, die Wujek hinterlassen hatte, war neben einer sehr sorgfältigen Übersetzung mit zahlreichen Textbemerkungen versehen. Am Rande fanden sich Vermerke, falls es Unterschiede zwischen der Vulgata und dem originellen Text gab. Die Kommentare zum Text - vorwiegend bei schwierigeren Stellen - waren ausführlich und hatten einen polemischen, sehr oft scharfen Charakter ${ }^{91}$. „Dotyczyły one bowiem - laut Bura - tych miejsc, które, zdaniem Wujka, zostały przez innowierców błędnie przetłumaczone"92.

Außerdem basierten sie nicht selten auf den Schriften der Kirchenväter, falls die Bedeutung eines Textfragmenten theologisch begründet werden muss-

${ }^{88}$ „Die Sprache von Wujek ist dem griechischen Original nahe, das in der sog. koine [...], also im allgemeinen Dialekt geschieben ist”. Ebd.

${ }^{89}$ Biblia w przektadzie..., S. XIX.

${ }^{90}$ Nach der Analyse des versammelten phraseologischen Materials schlussfolgert die schon erwähnte Renata Bura: „Większość związków frazeologicznych znajduje potwierdzenie już w Nowym Testamencie z 1593 roku, zaś mniej liczne zmiany, których dokonała komisja cenzorów, w większości okazały się poprawkami korzystnymi dla stylu przekładu”. Ebd., S. 19. Eine ähnliche Meinung in dieser Frage vertritt Stanisław Koziara: „Zdarzyło się jednak również, że zabiegi redaktorów Biblii z roku 1599 zmierzały w słusznym kierunku. I tak wyrażenia z tekstu autorskiego znamiona czasu (Mt 16,3), odzienie wesela (Mt 22,11), ptaki powietrzne (Mt $6,26)$ zmieniono na odpowiednie: znaki czasu, szata godowa, ptaki niebieskie. Podobnie uczyniono ze zwrotem rozdzierać odzienie (Mt 26,65), któremu w wydaniu pośmiertnym odpowiada forma rozdzierać szaty. Te ostatnie w rezultacie powiększyły zasób frazeologizmów biblijnych polszczyzny”. S. Koziara, O frazeologizmach..., S. 92.

${ }^{91}$ Diese umfangreichen, gegen die Andersgläubigen gerichteten Kommentare, verursachten, dass Wujek - wie M. Kossowska schreibt - „Pozbawił przez to podobne wyjaśnienia protestanckie smaku owocu zakazanego, wytrącił przeciwnikowi wyznaniowemu broń z ręki, wyposażając odbiorcę swego przekładu w podobną i nie mniej a często i precyzyjniej wykonaną". M. Kossowska, Biblia w j. polskim, Bd. I, Poznań 1968, S. 338.

92 „Sie bezogen sich nämlich auf diese Stellen, die durch Andersgläubige fälschlich übersetzt worden waren”. Ebd., S. 16. 
te. Denn es war - wie Frankowski erwähnt - eines der wichtigsten Ziele vom Priester Jakub Wujek, sich den ,Ketzern' zu widersetzen ${ }^{93}$.

Ging es Wujek aber nur um den religiösen Kampf? Irena Kwilecka ${ }^{94}$ findet, dass „w Polsce, podobnie jak w niektórych krajach Europy Zachodniej, nie było wyraźnego przedziału między przekładami katolickimi a innowierczymi. Mimo całej polemicznej wrzawy i obrzucania się do inwektywami, tłumaczy okresu Odrodzenia łączyło jedno wspólne pragnienie: wierne oddanie «szczyrego Słowa Bożego» i szczere nauki Chrystusowej"95. Eine solche humanistische Einstellung zur Übersetzung war gerade für Wujek kennzeichnend, der „mit vollem Bewusstsein” nach der „Brester Bibel”, dem Neuen Testament von Marcin Czechowicz oder der „Budny-Bibel” griff ${ }^{96}$.

Interessant scheint in diesem Zusammenhang die Bemerkung von Stanisław Koziara $^{97}$ zu sein, der aufgrund der vergleichenden Studien der biblischen Phraseologie festgestellt hat, dass „,w poszukiwaniu najbardziej odpowiednich form i konstrukcji Wujek o wiele częściej sięgał do przekładów protestanckich niż katolickich"98.

Aus der Brester Übersetzung schöpfte Wujek Konstruktionen, die auf Dauer in den traditionellen Bestand der pl. Phraseologie eingegangen sind, wie z. B.: jaskinia zbójców (Mt 21,13), statt jaskinia łotrowska (Leopolita, Bielski), oder jaskinia rozbójnicza (Budny); ferner dać świadectwo (J 5,33), Bóg jest mi świadkiem (Flp 1,8). Am Beispiel von Czechowicz führte Wujek dagegen die Wendungen ein: być dobrej myśli (Łk 12,19), mieć się źle (Mk 1,32), die bei keinem der Vorgänger vorhanden waren ${ }^{99}$.

93 „Zresztą jednym z zasadniczych celów ks. Wujka było przeciwstawienie się 'kacerzom"”. Biblia w przektadzie..., S. XIX.

${ }^{4}$ I. Kwilecka, Staropolskie przekłady Biblii i ich związi z biblistyka europejska. Zarys problematyki, [in:] Biblia a kultura Europy, Bd. II, Łódź 1992, S. 292.

95 „In Polen - ähnlich wie in manchen westeuropäischen Ländern - gab es keine deutliche Trennung zwischen den katholischen und andersgläubigen Übersetzungen. Trotz des ganzen polemischen Lärms und Getümmels und der gegenseitigen Überschüttung mit Schmähungen verband die Übersetzer der Renaissance ein gemeinsames Verlangen: ‘das Wort Gottes' und die Lehre von Christus 'aufrichtig' wieder zu geben”. Vgl. I. Kwilecka, ebd., S. 293.

96 Ebd., S. 293.

97 S. Koziara, O frazeologizmach..., S. 92.

98 „Auf der Suche nach den meist entsprechenden Formen und Konstruktionen griff Wujek viel öfter nach protestantischen als nach katholischen Übersetzungen". Diese Tatsache wird von S. Koziara mit folgenden Zahlenangaben belegt. Von der Gesamtzahl von 60 gewählter Beispiele stimmt die ,Wujek-Bibel” fast in 44 Fällen mit der „Brester Bibel” und mit der Übersetzung von Czechowicz überein. Weniger, denn bloß 37 Übereistimmungen lassen sich auf die katholische „Leopolita-Bibel” zurückführen, 32 - auf das Neue Testament von Bielski, am wenigsten - 27 auf die Übertragung von Budny. Ebd.

99 Mehr dazu, siehe S. Koziara, O frazeologizmach..., S. 92. 
Ein Teil der festen Wortverbindungen, die in derselben Form sowohl bei Wujek als auch in früheren Übersetzungen erschienen sind, sind Lehnprägungen aus dem Tschechischen, die sog. Bohemismen oder lateinische Entlehnungen, wie z. B.: dzień sądny - den súdný; ogień piekielny - pekelní oheń; sól ziemi sal terrae; oko za oko, a zą za ząb-oculum pro oculo, et dentem pro dente $e^{100}$.

Diese vielseitigen Bezüge, die der Übersetzer auf Suche nach der meist entsprechenden Sprache für seine eigene Übersetzung machte, zeugen davon, dass es Wujek vermochte, schöpferisch aus den Erfahrungen und Errungenschaften seiner Vorgänger Nutzen zu ziehen. Zweifellos trug seine moderne, überkonfessionelle translatorische Werkstatt dazu bei ${ }^{101}$.

Aber diese Kreativitat äußerte sich auch denn, dass Wujek keine Muster benutzte, sondern seinen eigenen Weg ging. So zum Beispiel ${ }^{102}$ gebrauchte er zum ersten Mal den Ausdruck wielka rzesza (Mt 20,29), statt tluszcza bardzo wielka (Leopolita, Budny), oder bardzo wiele ludzi (Biblia brzeska); die Wendung oddać ducha (J 19,30) statt podać ducha (Leopolita, Biblia brzeska, Budny) oder die Phrase padt strach (Dz 19,17) statt przyszedt strach (Biblia brzeska); przypadt strach (Leopolita).

Wujek verwendete als erster den Ausdruck ptaki powietrzne (Mt 6,26), der von den Zensoren gemäß alten Übersetzungen in ptaki niebieskie (łac. volatilia caeli) geändert wurde.

Auf diese Weise führte er als erster eine Reihe von Konstruktionen ein, die dauerhaft in den Kanon der biblischen Phraseologie im Pl. eingegangen sind, solche wie: dar Boży, znaki czasu, kamień wegielny, bić się w piersi, umywać ręce ${ }^{103}$.

Diese Beispiele zeigen, dass Wujek von der sklavenhaften Huldigung, sowohl dem Text der lateinischen Vulgata als auch den älteren herkömmlichen Übersetzungen, fern war. Dies bestätigt die allgemein vorherrschende Meinung, dass Jakub Wujek in der Übersetzungsarbeit den Traditionalismus mit der Neuerungssuche auf eine meisterhafte Weise zu vereinigen vermochte und die Notwendigkeit einsah, das von Gott inspirierte Wort in einer möglichst schönen und richtigen Form auszudrücken ${ }^{104}$.

\subsubsection{Modernisierungen der „Wujek-Bibel”}

Die „Wujek-Bibel” wurde über dreihundertfünfzig Jahre mehrmals nachgedruckt, und auch mehr oder weniger modernisiert ${ }^{105}$.

100 Ebd., S. 93.

101 Ebd., S. 93.

102 Beispiele nach S. Koziara, O frazeologizmach...

103 S. Koziara, Polszczyzna biblijna..., S. 198.

104 S. Koziara, O frazeologizmach..., S. 93.

105 Das Neue Testament oder seine Fragmente wurden rund 60 mal nachgedruckt, die ganze Bibel aus 1599 - circa 30 mal. Diese Angaben entnehme ich dem Werk von H. Duda, ,...kazda 
In den folgenden Wujek-Ausgaben tauchten schon seit dem 17. Jh. orthographische, grammatische und lexikalische Änderungen auf, die durch die natürliche Evolution der Sprache begründet waren.

Eine eingehende Modernisierung des ganzen Textes der Heiligen Schrift unter diesem Gesichtspunkt wurde zweimal, und zwar in der Zwischenkriegszeit durchgeführt. Zuerst war es eine 5-bändige „Posener Bibel”106, die durch das Autorenkollektiv unter der Leitung vom Priester Józef Archutowski 1926-1932 herausgegeben wurde und dann die „Krakauer Bibel” ${ }^{107}$ aus dem Jahre 1935, deren Verfasser die Jesuiten Stanisław Styś und Jan Rostworowski waren. Die Posener Ausgabe beinhaltete mehr Änderungen im Bereich des Alten Testaments, die Krakauer Ausgabe dagegen modernisierte die neutestamentliche Fassung von Wujek ${ }^{108}$.

Von den derartigen jüngsten Modernisierungen ist der Nachdruck der ganzen „Wujek-Bibel” aus 1599 in der Transkription des Typs „B” zu erwähnen, die die moderne Rechtsschreibung und Zeichensetzung beachtet und eine freie Textgliederung erlaubt. Diese Fassung - von Janusz Frankowski vorbereitet und mit seinem Vorwort versehen - wurde durch den Verlag „Vocatio” im Jahre 1998 herausgegeben.

\subsubsection{Rolle der „Wujek-Bibel” in der Sprachentwicklung}

Trotz zahlreicher Modernisierungen hat sich der Text von 1599 bis zur Gegenwart erhalten, d. h. de facto bis zur Veröffentlichung der ersten Ausgabe der „Millennium-Bibel” (1965), die nach der „Wujek-Bibel” die Rolle des in der katholischen Kirche gültigen Textes übernommen hat. Diese Tatsache, dass derselbe Text in der Sprachgeschichte über dreihundertfünfzig Jahre anwesend war, spielte eine wesentliche Rolle im Prozess der Gestaltung der Merkmale und Eigentümlichkeit des biblischen Stils in der pl. Sprache ${ }^{109}$.

Zusammenfassend: die Bibel von Jakub Wujek war durch die Jahrhunderte nicht nur die geistige Nahrung als das Wort Gottes, sondern auch ein literarisches Werk, auf das hin Generationen von Polen erzogen wurden und die auf die Entwicklung der allgemeinen Sprache und der pl. Literatur einen Einfluss hatte. Vom Stil der Bibelübersetzung waren die nationalen Dichter Adam Mickiewicz, Juliusz Słowacki und Cyprian Kamil Norwid geradezu entzückt. Ne-

raza Bibliq odmieniać”. Modernizacja języka przedruków Nowego Testamentu ks. Jakuba Wujka w XVII i XVIII wieku, Lublin 1998, S. 30.

${ }^{106}$ Pismo Święte w tlumaczeniu Ks. Jakuba Wujka, bearbeitet von J. Archutowski (und anderen), Poznań 1926-1932.

${ }_{107}$ Pismo Święte Starego i Nowego Testamentu w przekładzie Jakuba Wujka T.J. Tekst poprawiony [...], bearbeitet von S. Styś, J. Rostworowski, Kraków 1935.

${ }^{108}$ SWB, S. 652.

109 S. Koziara, Polszczyzna biblijna..., S. 188. 
ben den literarischen Vorzügen zeichnete die „Wujek-Bibel” sich auch durch theologische Gelehrsamkeit, Kenntnis der biblischen Exegese und Tradition aus. Dank dieser Vorteile fand sie die Anerkennung nicht nur in der katholischen Kirche, sondern wurde ebenso unter den Protestanten geschätzt.

\section{Quantitativer Vergleich von nl. und pl. Bibelübersetzungen}

\section{1. Ältere nl. und pl. Bibelübersetzungen ${ }^{110}$}

Die ersten christlich-lateinischen Lehnwörter und Bibelfragmente kamen über das Deutsche um das 8.-9. Jh. in die Niederlande. Nach Polen kamen sie über das Tschechische zwei Jahrhunderte später, d. h. um das 10.-11. Jh.

Die erste große Welle der Bibelübersetzungen begann in der Reformationszeit und brachte acht vollständige Bibelübersetzungen hervor, wovon im Druck drei katholische und fünf protestantische veröffentlicht wurden. Die wichtigste Rolle in der Sprachentwicklung spielte die protestantische „Staatenbibel" (1637). In Polen entstanden in dieser Zeit fünf vollständige Bibelübersetzungen: Im Druck erschienen zwei katholische und drei protestantische Bibeln. Die für die pl. Sprache und Kultur einflussreichste Bibelübersetzung war die katholische „Wujek-Bibel” aus 1599.

Trotz zahlreicher Versuche die „Staatenbibel” und die „Wujek-Bibel” zu modernisieren oder durch andere Übertragungen zu ersetzen, blieben sie über mehr als drei Jahrhunderte lang für die nl. Protestanten und die pl. Katholiken die maßgeblichen Bibeln.

Die meisten der gegenwärtig geläufigen Bibelphraseme finden in der „Staatenbibel” oder in der Übertragung von J. Wujek ihren Ursprung oder sind durch ihre Vermittlung populär geworden.

Neben der dominierenden Tradition der Bibelübersetzung aus den Originalsprachen in den Niederlanden (protestantische Auffassung) gab es die katholische, die dem lateinischen Vulgatatext treu zu bleiben versuchte. Fast bis in das 20. Jahrhundert hinein war die „Moerentorf-Bibel” aus 1599 die prägnanteste Bibelübertragung für die nl. Katholiken.

Der protestantischen Minderheit in Polen gelang es 1632, eine hervorragende Bibelübersetzung anzufertigen: die „Danziger Bibel”, die neben der katholischen „Wujek-Bibel” den pl. Bibelwortschatz und -stil entscheidend geprägt hat.

${ }^{110}$ Siehe Diagramme 1.4.3.1. und 1.4.3.2. 


\subsection{Diagramm statt Zusammenfassung}

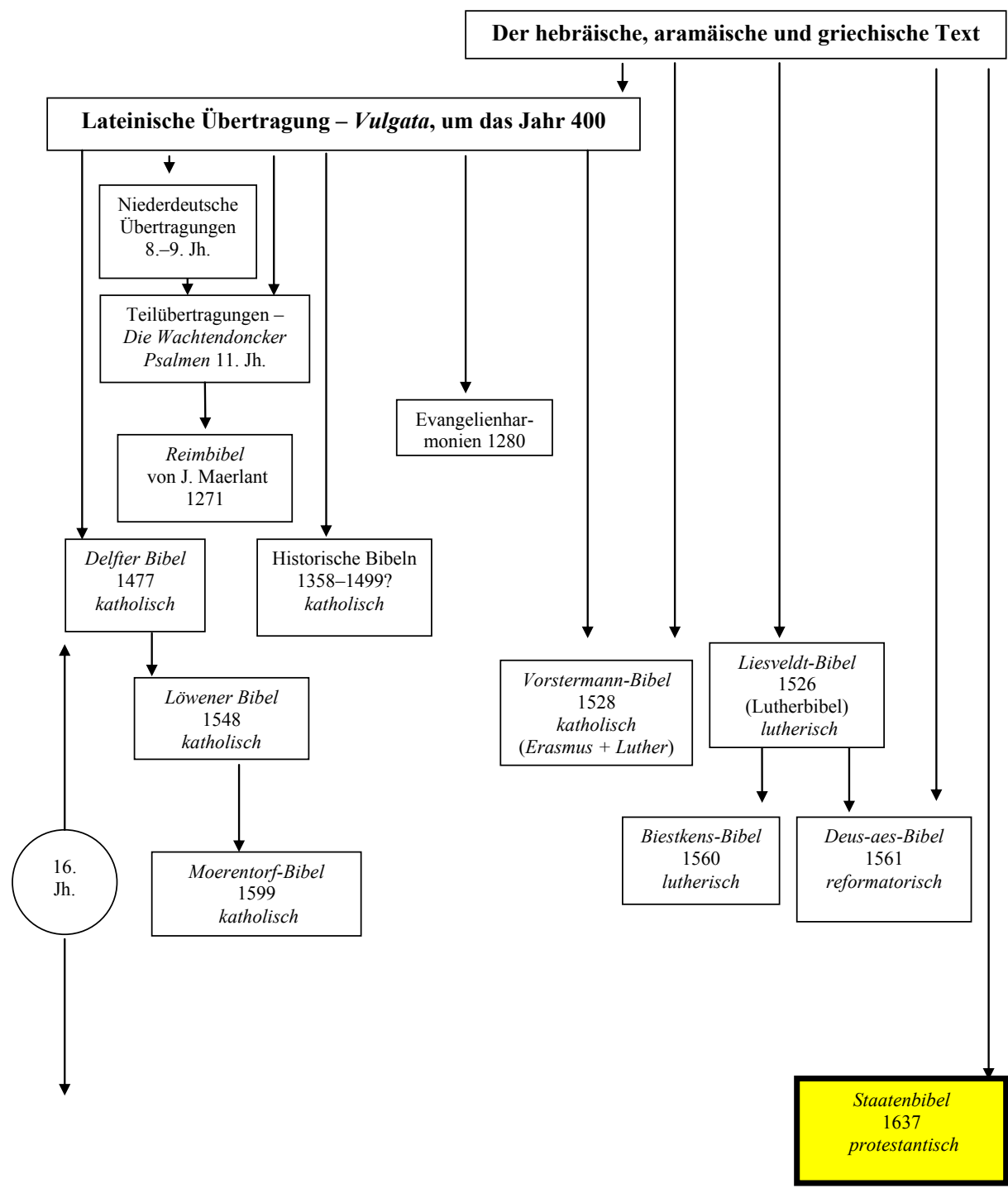

Diagramme 1. Wichtigere ältere nl. Bibelübertragungen 


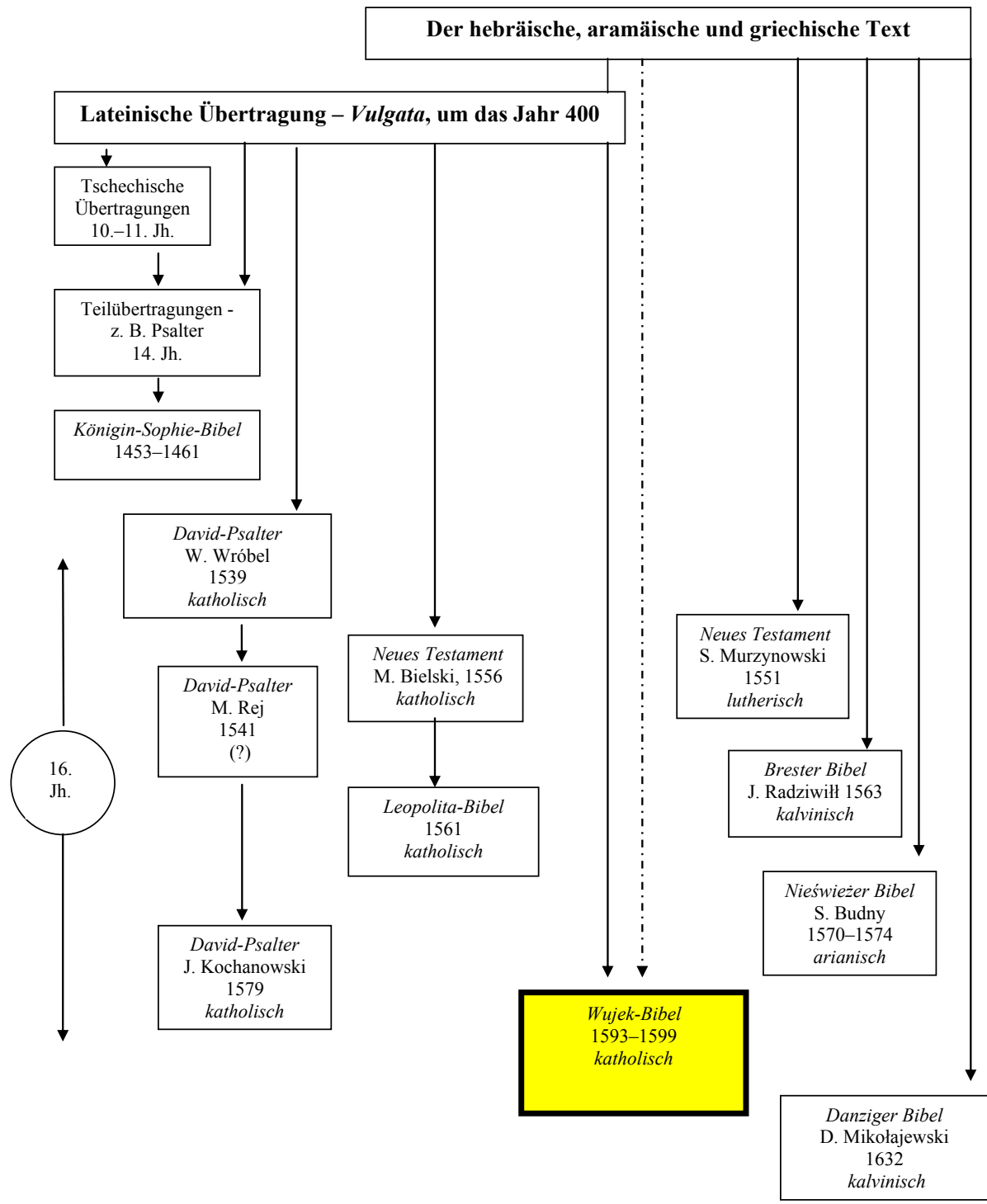

Diagramme 2. Wichtigere ältere pl. Bibelübertragungen 


\section{Mariusz Krajcarz}

\section{Old Dutch and Polish translations of the Bible}

The article is an attempt at a chronological presentation of the most important old and complete translations of the Bible by the time and including the Protestant Reformation in both compared languages. As for the Dutch language, eight Biblical translations have been analysed with Protestant translations prevailing (5). On the other hand, Polish is represented by five old translations of the Scriptures with a slight advantage of Protestant translations (3) over Catholic ones (2). Translations of the Bible largely affected the language and the style of the Scriptures. It is worth emphasizing that they were most influenced by the Protestant Staatenbijbel (1637) in the then Netherlands and by the Jakub Wujek Bible (1599) in Poland.

Key words: translations of the Bible in Dutch, translations of the Bible in Polish, Biblical phraseology in Dutch, Biblical phraseology in Polish.

dr Mariusz Krajcarz - Studium Języków Obcych Uniwersytetu im. Adama Mickiewicza w Poznaniu; germanista ze specjalizacją niderlandystyczną; zainteresowania badawcze: językoznawstwo niderlandzkie. 